\title{
Trama y urdimbre: hacia una biografía del sitio agropastoril Huayatayoc (Cusi Cusi, Puna de Jujuy, Argentina)
}

\section{Warp and weft: towards a biography of the Huayatayoc agropastoralist site (Cusi Cusi, Jujuy Puna, Argentina)}

\author{
M. Laura Pey ${ }^{1,2}$ https://orcid.org/0000-0002-0099-1751 \\ ${ }^{1}$ Instituto de Arqueología, Facultad de Filosofía y Letras, Universidad de Buenos Aires, \\ Buenos Aires, ARGENTINA. \\ ${ }^{2}$ Consejo Nacional de Investigaciones Científicas y Técnicas (CONICET), Buenos Aires, \\ ARGENTINA. Email: marialaurapey@gmail.com
}

\section{Resumen}

En este trabajo interpreto el historial ocupacional del sitio arqueológico Huayatayoc (Cusi Cusi, Puna de Jujuy) considerando la multiplicidad de prácticas y lógicas que pudieron interactuar en el habitar de este locus productivo a través del tiempo. El estudio de este caso me permite discutir el modelo interpretativo que se ha empleado en el estudio de la microrregión. Dicho modelo considera las lógicas pastoril y agrícola como excluyentes y discretas en el paisaje. Propongo la consideración de una tercera lógica -el agropastoreo-y realizo una primera aproximación hacia una analogía textil para interpretar la forma en la que estos modos de entender, construir y relacionarse con el entorno pudieron entrelazarse en el paisaje local.

Palabras claves: arqueología, puna seca, agropastoreo, agricultura de vega, Huayatayoc.

\begin{abstract}
In this article, I interpret the occupational history of the archaeological site of Huayatayoc (Cusi Cusi, Jujuy Puna) taking into consideration the multiplicity of practices and logics that would have underpinned dwelling at this productive locus over time. This case study allows me to consider the existing interpretative model used in the study of this region. This model posits pastoral and agricultural logics as exclusionary and discrete within the landscape. In turn, I propose we consider a third logic-agropastoralism. As such, in this preliminary approach I use a textile analogy to interpret the way in which these forms of understanding, constructing, and relating to the environment were intertwined with the local landscape.
\end{abstract}

Keywords: archaeology, dry puna, agropastoralism, wetland agriculture, Huayatayoc.

Recibido: 15 febrero 2019. Aceptado: 17 mayo 2019 


\section{Introducción}

En el presente trabajo propongo discutir y ampliar el enfoque que ha guiado la investigación sobre el paisaje productivo arqueológico de la microrregión de Cusi Cusi (Rinconada, Puna de Jujuy). Esta se ubica en la cuenca superior del Río Grande de San Juan -o San Juan Mayo- a 3800 msnm y su ambiente corresponde al de Puna Seca (Figura 1). Desde hace unos años me encuentro estudiando las estructuras agrícolas del área, lo que me ha permitido definir una serie de principios tecnológicos y de emplazamiento que han operado en la construcción de este paisaje (Pey, Zuccarelli y Carreras, 2015; Pey, 2016, 2017). En esta ocasión, las características particulares de uno de los sitios me invitan a discutir estos principios y abrir mis interpretaciones a un nuevo modelo interpretativo que contemple la multiplicidad de usos y lógicas que pudieron interactuar en el habitar de este lugar a lo largo del tiempo.

La mirada que guía mi investigación es la hermenéutica, una de las tantas perspectivas teóricas que se engloban dentro de lo que conocemos como Arqueología del Paisaje (Tilley, 1994; Barrett, 1999; Vaquer, 2011, 2013). La hermenéutica propone que en el proceso de habitar un paisaje -o dwelling, en términos de Ingold (Ingold, 1993, 2000) - cada sociedad posee una forma particular de entender y relacionarse con el mundo circundante. Estos modos diferenciales de habitar son lo que Vaquer denomina "lógicas del paisaje" (Vaquer, 2013). Dichas lógicas se encuentran estrechamente relacionadas tanto con las prácticas que desarrollamos los agentes en un espacio y un tiempo determinados como con sus consecuencias materiales. Un aspecto a destacar de esta relación es que se desarrolla de manera recursiva. El paisaje se encuentra estructurado por las prácticas de quienes lo habitamos -según nuestros propios principios lógicos- mientras que, a su vez, se comporta como un horizonte de inteligibilidad o de comprensión brindándonos recursos materiales para llevar a cabo nuestras actividades. Se trata de una relación recursiva en tanto que realizar actividades en el paisaje implica la producción y reproducción estructural de las sociedades. Por este motivo, si bien

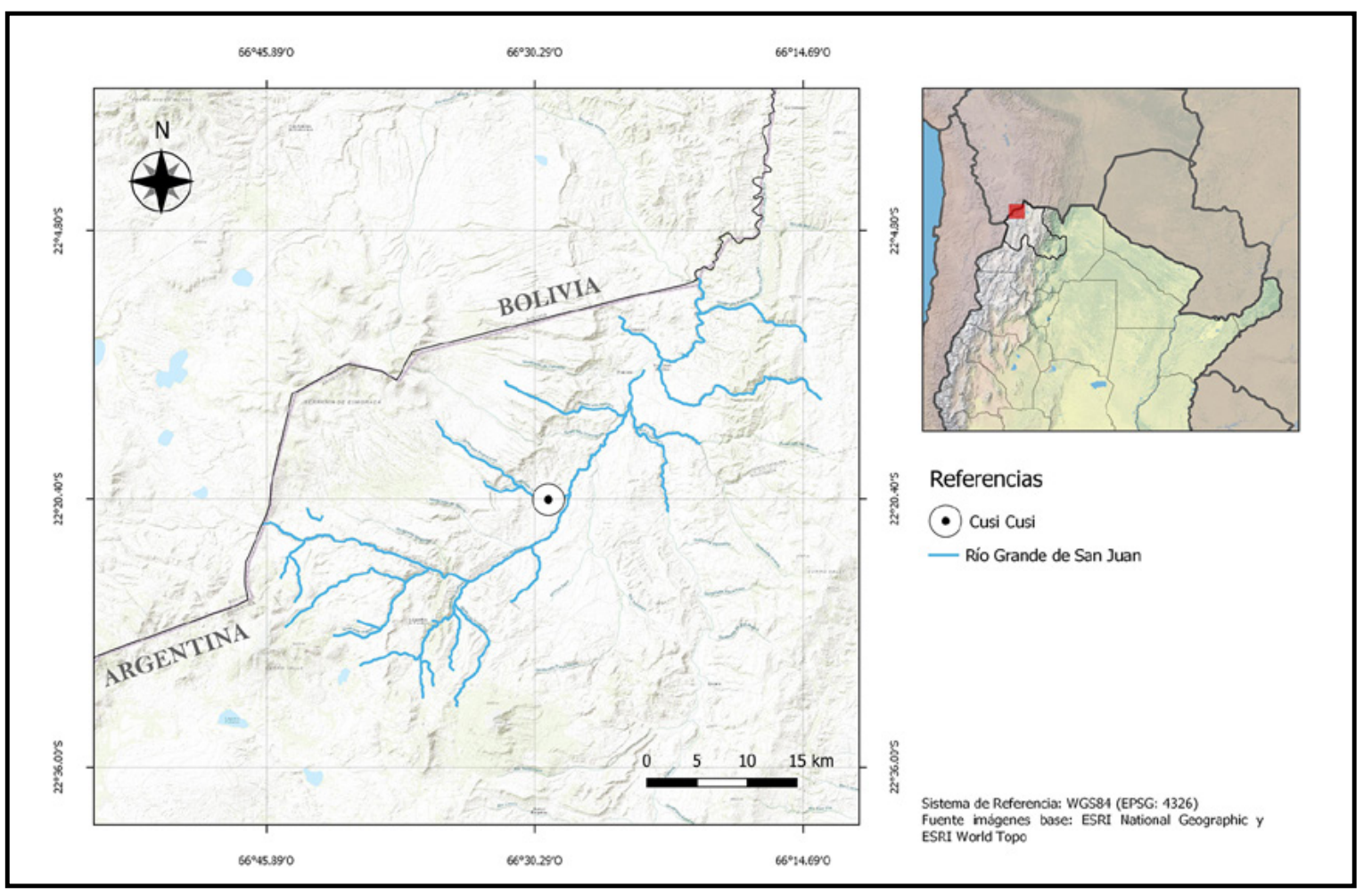

Figura 1. Área de estudio. 
previamente se ha explicitado la correlación entre las lógicas de habitar y distintos modos de producción -por ejemplo, las denominadas "lógica pastoril y "lógica cazadora-recolectora" de Cusi Cusi (Vaquer, 2016)-, se trata de un concepto que trasciende el plano meramente económico, abarcando aspectos organizacionales e interpretativos de cada sociedad en cuestión.

Es importante destacar que dentro de un mismo paisaje pueden coexistir distintas lógicas y, aunque cada una remita a una temporalidad determinada, sus consecuencias materiales trascienden dicha cronología, sedimentándose en el paisaje junto a otras -ya sean pasadas o presentes. El paisaje, entonces, se compone de un entramado de lógicas y sus consecuencias materiales que, a su vez, nos remiten a otras temporalidades. En este trabajo discutiré los alcances analíticos de dos de estas maneras de relacionarse con el entorno -la pastoril y la agrícola- aplicadas en la microrregión de estudio. Hasta el momento, en el área de estudio ambas han sido trabajadas como formas excluyentes y con locaciones discretas en el paisaje.

Teniendo esto en consideración, mi intención es explorar la posibilidad de encuentro de estas dos lógicas en Cusi Cusi a partir del estudio de un caso particular que tiene lugar en una vega: el sitio arqueológico Huayatayoc. En la actualidad, dicha vega es irrigada y mantenida empleando antiguos reservorios con el objetivo de alimentar una tropilla de llamas. Sin embargo, en otros tiempos, estos reservorios supieron irrigar los andenes y terrazas de cultivo que ahora allí yacen en desuso (al menos, en términos agrícolas). Entonces, me pregunto hasta qué punto se trata de lógicas excluyentes; cómo se pudieron relacionar en el tiempo dentro de un mismo espacio productivo; y evalúo la posibilidad de incorporar en la interpretación una tercera lógica, la agropastoril.

A continuación, presentaré una breve caracterización de las lógicas pastoril, agrícola y agropastoril para el área andina en general. Luego, introduciré las características del área de estudio contemplando, por un lado, las condiciones ambientales que posibilitan el desarrollo de estas actividades y, por el otro, los antecedentes de investigación. Más tarde presentaré los datos obtenidos a partir del trabajo de campo y laboratorio en Huayatayoc, para, finalmente, interpretar la multiplicidad de usos y lógicas que pudieron interactuar tanto en el diseño del sitio como durante el habitar en el tiempo.

\section{Pastores y agricultores andinos}

\section{Sobre la lógica pastoril}

Según la amplia definición de Chang y Koster (1986), el pastoreo o pastoralismo es un sistema de dependencia sobre rebaños de animales domésticos tenidos en propiedad. En la puna surge a partir del proceso de domesticación de camélidos que se desarrolló durante el Arcaico Tardío u Holoceno Medio II (Yacobaccio, 2013), y en algunos sectores -como ocurre en Cusi Cusi- continúa hasta nuestros días. Los rebaños pueden estar compuestos por una especie o ser mixtos. Suelen contar con llamas (Llama glama), ovejas (Ovis aries) y/o cabras (Capra hircus), estas dos últimas de introducción europea.

Si se emplea el modelo clasificatorio de Khazanov (1994), los pastores andinos podrían ser caracterizados como pastores trashumantes; a pesar de que este autor dude de la existencia de un verdadero pastoreo en los Andes. Esto significa que siguen los movimientos estacionales regulares del ganado entre áreas de pastoreo bien definidas. En la puna, las estaciones que marcan dichos movimientos son dos: la estación húmeda (de diciembre a marzo) y la seca (de marzo a noviembre). Esta movilidad determina dos aspectos esenciales para comprender a las sociedades pastoriles.

En primer lugar, su modo de vida se caracteriza por un patrón poblacional disperso en el paisaje (Flores Ochoa, 1968; Nielsen, 2003; Tomasi, 2013). El sistema de asentamiento pastoril se articula en torno a un núcleo aldeano central comunitario y varias localidades menores dependientes de este, pertenecientes a diferentes familias. El espacio reconocido por cada una de las comunidades suele delimitarse por marcadores naturales o apachetas (montículos de piedra) (Villagrán y Castro, 1997). De acuerdo con los estudios de Göbel (2002) y Yacobaccio et al. (1998), dicho sistema se compone de elementos 
arquitectónicos puntuales tales como los llamados "puestos" o estancias emplazados en zonas cercanas al agua (humedales y quebradas) dentro del área de pastoreo asignada a cada unidad doméstica. Los puestos cuentan con uno o más recintos habitacionales, corrales y pequeñas huertas; y suelen ubicarse en diferentes pisos ecológicos para aprovechar distintas pasturas según la estación. En el Loa Superior (Norte de Chile), Villagrán y Castro (1997) identifican además otros tipos de locaciones como las "camas de arriero", es decir, grandes abrigos rocosos localizados en taludes de altas quebradas y cerrados por un muro, que son habitados durante una o dos semanas. También han registrado ocupaciones de no más de un día o dos en aleros rocosos más pequeños ("balconcitos") y estructuras conformadas por muritos con unas pocas hiladas de piedras (o parapetos), para protegerse del sol y el viento, tallar lítico y/o para cazar mientras se pastorea. Finalmente, el patrón estanciero se completa con una casa central o "casa de campo" y una casa en el núcleo aldeano -clave a la hora de escolarizar a los niños o realizar tareas administrativas y comerciales-.

En segundo lugar, como sugiere Cribb (1991), la lógica pastoril no solo implica un modo de producción, sino también un modo particular de percibir el mundo basado en el "thinking nomadic" (pensar nómade). Para este autor, son pastores aquellos grupos que se autodefinen como tales y organizan todo su tiempo diario y estacional alrededor del movimiento y las necesidades de sus animales. Dicha movilidad no solo requiere un profundo conocimiento del territorio, sino que, además, versa sobre lugares familiares y que son visitados recurrentemente (Castro, Varela, Aldunate y Araneda, 2004). Los cerros se encuentran surcados por extensos caminos con un largo historial; y muchos de ellos, a sus veras, presentan apachetas, ofrendas y otros tantos marcadores del paisaje (Nielsen, 2000). A su vez, dispersas por los cerros, preferentemente en lugares elevados, se construyen trampas para zorros y/o chullpas (más adelante se explicitarán las características de estas estructuras). Otro aspecto que quiero destacar es el hecho de que, si bien en muchos casos el pastoreo se combina con el cultivo de algunos vegetales -por ejemplo, los mencionados huertos asociados a puestos-, la inversión de tiempo en el trabajo agrícola respecto de la actividad ganadera es mínima.

\section{Sobre la lógica agrícola}

El modo de vida agricultor andino se asocia principalmente al surgimiento de grupos formativos -sensu Olivera (2001) - con aglomerados habitacionales, una relativa reducción de la movilidad respecto de la lógica pastoril y el desarrollo del conocimiento técnico necesario para incrementar la producción vegetal. Vale aclarar que, al igual que ocurre con el pastoreo, en los Andes el modo de vida campesino centrado en la agricultura se extiende hasta nuestros días como, por ejemplo, los agricultores de Huaquirca en Perú (Gose, 2004) o los del Norte de Lípez (Potosí) en Bolivia (Guagliardo, 2011).

Obtener una producción agrícola constante en un ambiente como la puna implica una modificación drástica del paisaje que permita a los agricultores controlar la composición, el grosor y la humedad de los suelos, así como la temperatura adecuada para los cultivos (Treacy, 1994). Para ello, desde tiempos muy tempranos los agricultores y agricultoras han sabido idear diversas obras arquitectónicas tales como sistemas de terrazas y extensas redes de irrigación mediante la construcción de reservorios y acequias. A su vez, han construido pircados para proteger el cultivo de vientos y animales, estructuras de almacenamiento y plataformas destinadas a la trilla y/o procesado de la cosecha, entre otras (Erickson, 2006). Cabe destacar que el agricultor andino suele tener sus cultivos a distintos niveles altitudinales por ejemplo, en los cerros y los fondos de valle-, para evitar, en caso de desmejorías climáticas, la pérdida total del cultivo (Mamaní, 1988).

La agricultura andina siempre ha procurado ser sostenible (Rist y San Martin, 1993). Siguiendo esta línea, los dos principios básicos que guían la actividad son el ciclo de rotación de cultivos y el sistema de barbecho sectorial. El ciclo de rotación de cultivos establece un orden de siembra para un terreno determinado y depende de la calidad de su suelo. Si este se encuentra muy empobrecido, por ejemplo, suele plantarse primeramente tarwi (Lupinus mutabilis), ya que aporta el nitrógeno necesario para su nutrición. Al año siguiente, entonces, puede sembrarse papa (Solanum tuberosum) y, luego, quinua (Chenopodium quinoa) (Mamaní, 1988). Por cierto, no todas las tierras son trabajadas a la vez sino 
por sectores, pues la máxima que prima es evitar el desgaste de la tierra mediante el descanso (Orlov, Karavanova y Pankova, 1992). Así como los tiempos del pastor son los del ganado, los del agricultor son los del cultivo. La fenología -o la interpretación de las señas presentes en el paisaje- y la astronomía le proporcionan al agricultor andino conocimientos que le ayudan a organizar su vida y determinar los tiempos adecuados para la actividad productiva (Mamaní, 1988; Enríquez Salas, 2000; Van Kessel y Enríquez Salas, 2002). La temporalidad en las sociedades agrícolas andinas siempre ha estado marcada por la cadencia del calendario agrícola, una cadencia vinculada estrechamente con los cambios en los elementos biológicos del paisaje andino, las lluvias y los movimientos del paisaje astral.

\section{Una tercera lógica, el agropastoralismo}

El agropastoralismo o agropastoreo, según Browman (1990), es una forma de producción altamente especializada que enfatiza el control del riesgo ambiental a través de la diversificación, es decir, la combinación de diferentes actividades económicas. Esta forma de producir y de pensar el entorno de manera combinada se desarrolla en los sectores de transición entre los pisos de agricultura (suni) y de pastoreo (puna), entre los 3800 y los $4200 \mathrm{msnm}$. Son sectores de encuentro de agricultores que tienen algunos animales ("mixed farmers") con pastores con pequeños cultivos. Se considera que fue a partir de una relación muy estrecha entre ambos grupos que surgió el agropastoreo en los Andes Centrales (Lane 2006a).

Lane (2006b) advierte que no se trata tan solo de sociedades pastoriles con un poco de agricultura -estos serían pastores, ya que como vimos anteriormente, desde una definición amplia se acepta la complementación con cultivos-; se trata de una forma diversificada de pastoreo que integra las prácticas agrícolas y puede hacerlo con diferentes grados de intensificación. De hecho, una misma comunidad puede ir cambiando la intensidad que le brinda al pastoreo o a la agricultura de acuerdo con cambios en el contexto político, social o ecológico. En los Andes, existen muchos tipos de comunidades agropastoriles pero todas comparten una característica: su vida está organizada alrededor de la producción ganadera.
Un ejemplo arqueológico de agropastoralismo que se ha registrado en los Andes Norcentrales (Perú), es el valle de Chorrillos en la cordillera Negra. Allí, entre los 3500 y 4900 msnm se emplaza un sistema de voluminosas represas de limo con grandes canales y reservorios de agua, cercanos a terrazas y puestos pastoriles con corrales antiguos. Lane (2006a, 2006b) propone que la construcción de dicha arquitectura hidráulica corresponde al Período Intermedio Tardío (900-1480 años DC) y, contrario a lo que se esperaría, se utilizaba más para el pastoreo que para la agricultura. De hecho, uno de los objetivos de la acumulación de limo era crear grandes humedales donde pastara la hacienda. Si bien a nivel altitudinal, este sector se encuentra en una franja aún propicia para el cultivo, los antiguos pobladores eligieron emplearla principalmente para el pastoreo, hecho que el autor interpreta como una clara expresión de la política ecológica agropastoril del momento.

\section{El área de estudio}

\section{Las condiciones ambientales}

Como mencioné previamente, la cuenca superior del Río Grande de San Juan se encuentra en la Puna Seca de Jujuy. Esta es un semidesierto de altura surcado por cordones montañosos de dirección NESW y que abarcan un rango altitudinal entre los 3600 y $4500 \mathrm{msnm}$. El clima es frío y seco, con temperaturas medias anuales de 3 a $6{ }^{\circ} \mathrm{C}$, heladas casi todo el año y nieve en los meses de invierno. Cuenta con una alta evapotranspiración, elevada radiación solar y una gran amplitud térmica diaria que abarca desde los $30{ }^{\circ} \mathrm{C}$ diurnos hasta temperaturas nocturnas inferiores a los $-20{ }^{\circ} \mathrm{C}$ en los meses más fríos. Se caracteriza por una estacionalidad bien marcada -al menos el $80 \%$ de las lluvias se concentran en el período de diciembre-marzo- y la escasez de estas, oscilando entre 200 y $400 \mathrm{~mm}$ anuales. Quedan así definidas las dos estaciones antes mencionadas (la estación seca y la húmeda) (Saravia, 1960; Buitrago, 1999).

En términos generales, la vegetación corresponde a la provincia fitogeográfica puneña, sensu Oyarzabal et al. (2018), donde predomina la vegetación xerofítica. Esta se encuentra adaptada a la falta de 
agua, las bajas temperaturas y al pastoreo. Ejemplos de este tipo de vegetación son las plantas con raíces profundas (Adesmia schickendanzii); tejidos de almacenamiento de agua (Tephrocactus spp.); hojas pequeñas o tallos fotosintéticos (Fabiana denudata), espinas (Aloysia salsoloides), o plantas en cojín o placa a ras del suelo (Werneria aretioides, Azorella compacta). Predomina la estepa arbustiva baja, caracterizada por la presencia de tolas (Fabiana densa, Baccharis boliviensis, Baccharis incarum) y paja ichu (Stipa ichu). También se registran cactus aislados y cardones (Echinopsis atacamensis).

En general, la evolución de los suelos es muy lenta debido a la sequedad y la capa húmica es delgada y discontinua. Además, el desarrollo de la materia orgánica se ve dificultado por el frío, sufriendo una leve mineralización. Se trata de un tipo de ambiente muy fragmentado en el que las únicas fuentes de agua disponible son unas pocas cuencas permanentes de agua dulce y unas pequeñas vertientes dispersas a lo largo del paisaje. En este escenario, la productividad primaria se concentra principalmente en sistemas estables como cuencas primarias, valles elevados y humedales (Dollfus, 1991). Sobre estos últimos me interesa reparar especialmente.

Los humedales son pastizales de alta cobertura $(>70 \%)$ y elevada productividad que pueden presentarse a diversas altitudes; se ubican de manera discreta en el espacio y están fuertemente asociados a sistemas hídricos estables o vertientes (ya sean superficiales o subterráneas). Allí se desarrollan suelos con un alto contenido de materia orgánica donde suelen crecer una gran diversidad de hierbas dicotiledóneas y graminoides (Gonnet, López, Aranibar y Lictevout, 2016). El tipo de parche fisonómico de la vegetación depende de la altitud, de los caudales de alimentación y de las características fisicoquímicas de las aguas. Cada parche puede ser homogéneo, o bien heterogéneo y presentar una combinación de comunidades vegetales con plantas dominantes de diferente arquitectura o forma de crecimiento. Según se dé esta composición, se distinguen tres tipos de parches: los pajonales (donde predominan los pastos altos de más de $1 \mathrm{~m}$ de los géneros Deyeuxia y Festuca), las praderas de céspedes (donde predominan graminoides bajos, de menos de $20 \mathrm{~cm}$, como las Juncaceae, Cyperaceae y
Graminae) y, por último, las comunidades vegetales dominadas por plantas de crecimiento en cojín de los géneros Oxychloe, Patosia y Distichia (Juncáceas) y Zameioscirpus (Familia Cyperaceae). A estos tres grandes grupos, acompañan hierbas dicotiledóneas rastreras o en roseta. A menores altitudes, en hábitats precordilleranos y quebradas, los humedales pueden presentarse como pajonales altos (de más de $3 \mathrm{~m}$ ) de cortaderas (Cortaderia spp), denominados cortaderales (Gonnet, López, Aranibar y Lictevout, 2016). En síntesis, los humedales de altura son verdaderos oasis que presentan dos tipos de forrajes complementarios. Por una parte, plantas tiernas y pequeñas y, por otra, vegetación de tipo paja (Haber, 1991; Squeo et al., 1993).

Existen muchas formas de referirse a estos sectores húmedos. Las comunidades de los Andes Centrales (Perú) suelen denominarlos "oconales" (derivado de $o k^{\prime} o$, humedad en quechua). En comunidades quechua de Atacama y Jujuy se les llama "ciénagos", y, en muchas publicaciones científicas, "vegas" o "bofedales" (Lane 2006a; Maldonado Fonken, 2014/2015; Gonnet et al., 2016). Sin embargo, en las clasificaciones más actuales, el término bofedal refiere estrictamente a los parches que se forman entre los 4000 y los $4800 \mathrm{msnm}$; poseen elevada y constante disponibilidad de humedad durante todo el ańo; y donde predomina la vegetación en cojín, principalmente las juncáceas Distichia muscoides Nees y Meyen, y Oxychloë andina Phil (Squeo, Warner, Aravena y Espinosa 2006; Torres et al., 2012).

Los pastos de los humedales altoandinos tienen un alto valor nutritivo y son muy apetecidos por los camélidos (Palacios Ríos, 1988). Allí radica la importancia de las vegas para el pastoreo. Tener acceso a una de ellas, con disponibilidad de agua y pastos naturales, es algo muy apreciado por los pastores puneños. De hecho, un aspecto para destacar es que estos humedales pueden ser de origen natural o antrópico. Tal es el caso, por ejemplo, de los antes mencionados humedales de la cordillera Negra en Perú. Más adelante profundizaré sobre las prácticas que dan origen y/o continuidad a este tipo de vegetación. 


\section{Pastores y agricultores en Cusi Cusi}

El modelo que se ha desarrollado para interpretar las sucesivas ocupaciones de Cusi Cusi, desde tiempos prehispánicos hasta la actualidad, identifica seis lógicas o formas de relacionarse con el paisaje: una lógica cazadora-recolectora, una pastoril, una agrícola, una mercantil-colonial, una lógica que engloba las interpretaciones que los vecinos y vecinas actuales del poblado de Cusi Cusi realizan sobre el paisaje local y, finalmente, la lógica de quienes investigamos el área desde una mirada científica (Vaquer y Cámera, 2018). Como ya he anticipado, en este trabajo me enfocaré en la pastoril y la agrícola, que han sido trabajadas de manera excluyente según las características distintivas de sus restos materiales y la distribución espacial en el paisaje (Carreras, 2015; Pey, 2016; Vaquer, Gerola, Carboni y Bonelli, 2014).

Se ha propuesto que la lógica pastoril orientó el habitar de las poblaciones locales $-y$, por lo tanto, configuró el paisaje local- desde el Período Arcaico Tardío u Holoceno Medio II hasta el Período de Desarrollos Regionales Tardío (1200-1450 ańos DC). Se han identificado parapetos y talleres de producción lítica asociados a diferentes momentos dentro de este rango temporal según las características de los artefactos líticos hallados en superficie (Vaquer et al., 2014). También se ha estudiado el patrón de asentamiento pastoril actual -centrado en el poblado de Cusi Cusi-, focalizándose especialmente en los puestos y sus estructuras de combustión (Carreras, 2015). Los puestos pastoriles cuseńos, en general, se encuentran asociados a cursos de agua permanente. En sus inmediaciones se ha identificado material arqueológico prehispánico, por lo que se ha interpretado una reutilización de estos lugares en el tiempo.

A partir del Período de Desarrollos Regionales Tardío, se evidencia un aprovechamiento intensivo de sectores óptimos para el cultivo a través de la construcción de elaborados sistemas de riego y de andenería que dan cuenta del desarrollo -o introducciónde una nueva lógica al paisaje de la microrregión (Pey, 2016). Acompañando el surgimiento de la infraestructura agrícola, a partir de este período se evidencia la intrusión de material cerámico procedente del área de Casabindo y Yavi (Vaquer y Cámera,
2018). El paisaje agrícola se encuentra restringido a ciertos sectores privilegiados por sus condiciones topográficas y edáficas, su orientación respecto del sol y abrigo y su cercanía a fuentes de agua (Pey, 2017a). Las estructuras agrícolas arqueológicas se concentran principalmente en las quebradas de Pajchela y Huayatayoc, ocupando un área de aproximadamente 60 ha (Figura 2). Los principales sitios productivos son: en la quebrada de Pajchela, el Complejo Agrícola Pajchela (compuesto por los sitios Casas Quemadas, Pajchela Núcleo y Sector Terrazas), y en la quebrada de Huayatayoc, los sectores Alto y Bajo.

En la actualidad, gran parte de los andenes y terrazas se encuentran en desuso mientras que, unos pocos, son reutilizadas con fines agrícolas y/o pastoriles. Esto se debe a que, hoy en día, Cusi Cusi es un pueblo pastoril con muy baja inversión en la actividad agrícola. Desde tiempos históricos, las prácticas de cultivo se desarrollan a nivel familiar y en una escala limitada al autoconsumo. ${ }^{1}$. Algunas familias poseen su propia huerta de no más de una hectárea donde suelen sembrar una limitada variedad de hortalizas y tubérculos, como papas, habas, cebollas, zanahorias, entre otras (Pey, 2017b).

En este trabajo me centraré en el sitio Huayatayoc, específicamente en el sector Alto, habitado y trabajado por la familia Quispe desde hace generaciones. Se ubica a $3,3 \mathrm{~km}$ al noroeste del pueblo y se emplaza a $3790 \mathrm{msnm}$. Ocupa un área de cerca de 12 ha en la margen derecha de la quebrada del río homónimo, que corre en dirección NW-SE. Geomorfológicamente se localiza sobre un depósito de deslizamiento. Desde sus primeras menciones en la bibliografía arqueológica fue caracterizado como un sitio de producción agrícola (De Feo, Fernández y Raviña, 2004; Vaquer, Zuccarelli, Pey y Cámera, 2014). Debido a las dimensiones y complejidad de su sistema de andenerías fue asociado tentativamente al Período Inka (1450-1536 DC) por De Feo et al. (2004), pero aún no contamos con fechados que permitan avalar esta hipótesis (Figura 3). A su vez, en superficie hemos hallado una gran cantidad de

1 Aunque en los últimos años se ha incentivado la producción de quinua a partir de la conformación de la cooperativa agrícola Cadecal. Los socios producen anualmente un promedio de una tonelada por hectárea para el acopio y posterior venta conjunta (ver Pey, 2017b). 


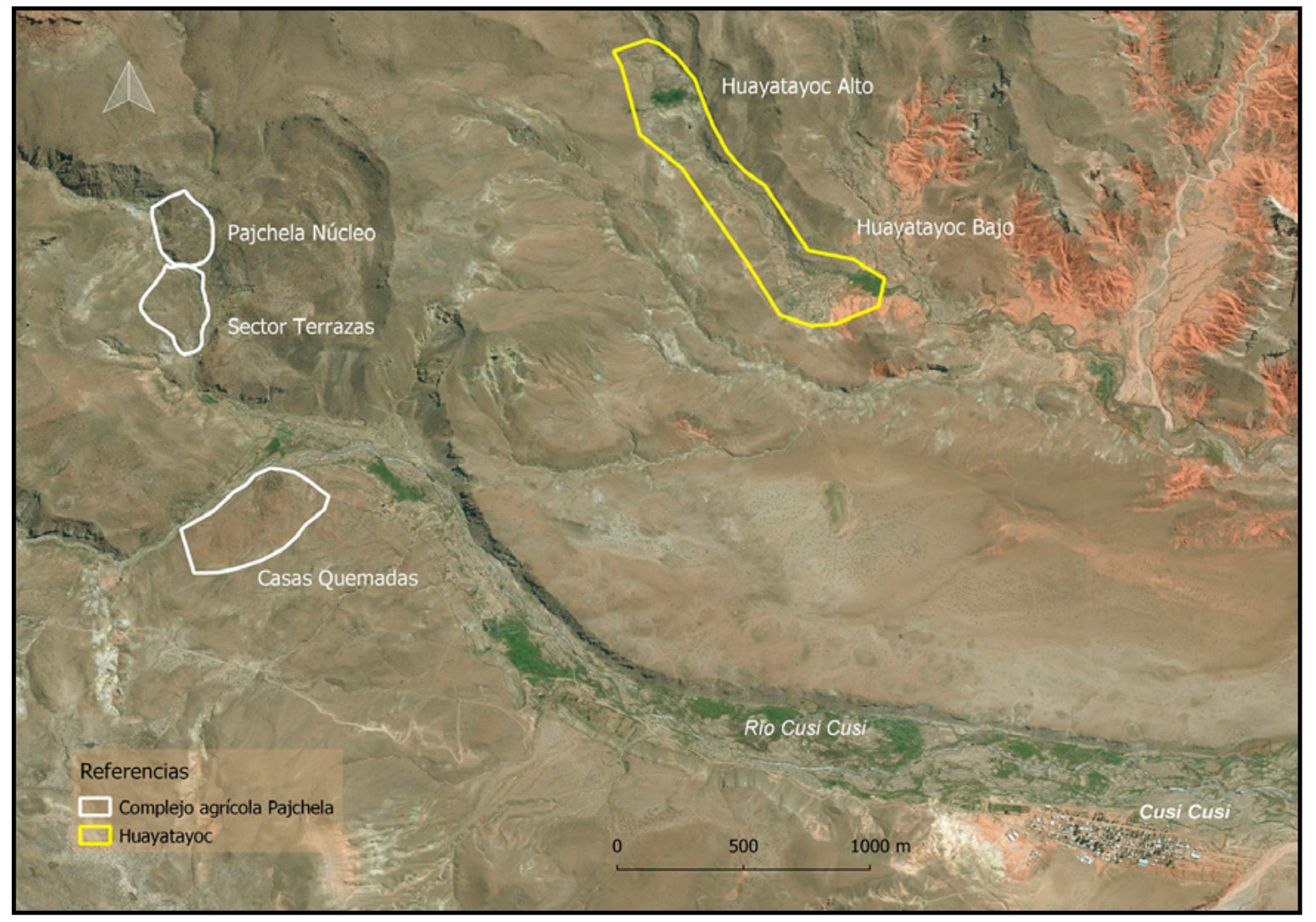

Figura 2. Distribución del paisaje agrícola arqueológico del área de Cusi Cusi.

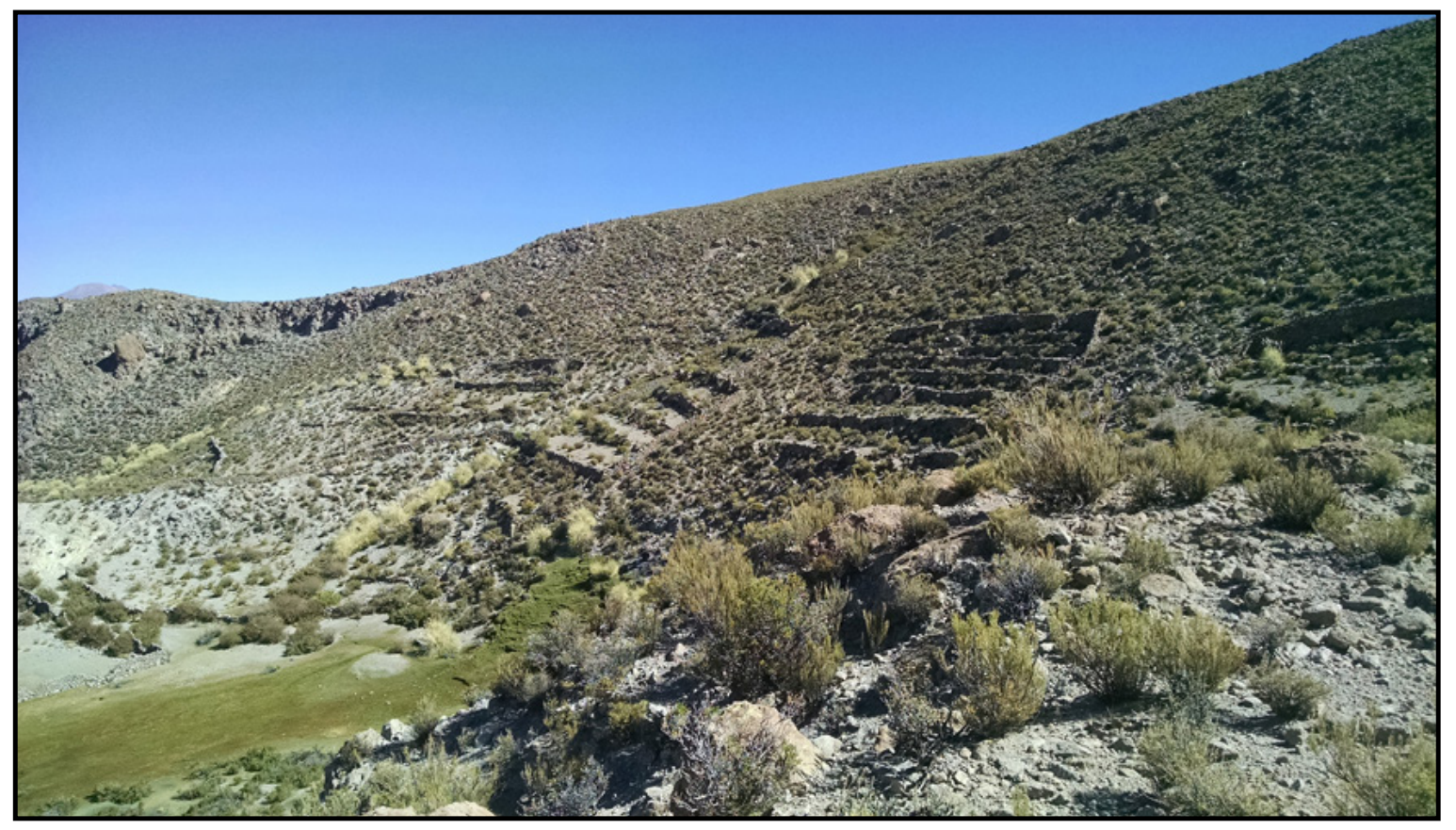

Figura 3. Andenes del sector B de Huayatayoc desde el norte. 
fragmentos de palas líticas de dacita; algunos torteros o phirarus de cerámica; y tiestos cerámicos pertenecientes a diferentes grupos tipológicos de variados momentos cronológicos y regiones (Yavi, Loa, Casabindo, Mallku, entre otros).

\section{Herramientas metodológicas}

\section{En el campo}

En términos generales, mi investigación en Huayatayoc implicó dos etapas de trabajo. La primera se llevó a cabo en el campo mediante una serie de campañas durante las que se realizó el levantamiento planialtimétrico del sitio a través del empleo de una Estación Total (KOLIDA KTS-442R6LC) y un croquis a mano alzada. Para facilitar el relevamiento y posterior análisis se dividió el sitio en sectores arbitrarios. También se tomaron puntos de control para la posterior georreferenciación de la información capturada. Para ello se seleccionaron puntos del paisaje estratégicos y se empleó un GPS (Garmin GPSMAP 64 con receptor GPS y GLONASS configurado en WGS84).

A la par se realizó un detallado registro fotográfico de todas las estructuras que componen el sitio. También se registraron una serie de variables arquitectónicas para cada una teniendo en cuenta sus dimensiones generales; la orientación y las características de microemplazamiento dentro del sitio. Se realizó una descripción de los muros considerando medidas (alto, ancho y largo), tipo de hilada y aparejo, material constructivo, presencia o ausencia de mortero, estado de conservación y rasgos asociados. Además se realizó una clasificación tentativa in situ de cada estructura según su funcionalidad aparente y las características formales antes detalladas. Los tipos considerados fueron:

- Cuadros o canchones de cultivo: amplias áreas cuadrangulares o irregulares empleadas para el cultivo. Suelen estar definidas por un muro perimetral, aunque en algunos sitios de la microrregión se han presentado casos donde está ausente (Pey, 2016). Pueden poseer terrazas o desniveles internos, siempre se encuentran atravesados o asociados a canales de riego y generalmente presentan fragmentos de palas líticas en su superficie.

- Terrazas: Denevan las define como "superficies de cultivo que han sido allanadas o donde la pendiente ha sido reducida y que poseen un muro de contención normalmente de piedra" (Denevan, 1980, p. 622). En la clasificación que he empleado para el área, siguiendo a $\mathrm{Al}$ beck (1993), reservé esta categoría para referirme a aquellas que se ubican en terrenos con poca pendiente, conformando largas superficies rectangulares (o irregulares) transversales al drenaje principal. La altura de sus muros es muy variable, registrándose alturas mínimas de 0,20 m y máximas de $1,40 \mathrm{~m}$; el ancho de la terraza suele ser mayor que $5 \mathrm{~m}$; y el largo, como mínimo, alcanza los $15 \mathrm{~m}$. Las terrazas de Cusi Cusi, al igual que los canchones y los andenes, siempre se encuentran irrigadas. Denomino sistema de terrazas al conjunto de terrazas que se ubican de manera sucesiva y se encuentran irrigadas por los mismos canales.

- Andenes: son las superficies niveladas denominadas lateral o contour terraces (Donkin, 1979) o terrazas en banca (Denevan, 1980). A diferencia de las terrazas, se emplazan paralelos al drenaje principal sobre las laderas serranas, en terrenos con mayor pendiente. Los muros de contención son más elevados, superando los 0,5 $\mathrm{m}$ y alcanzado una altura máxima de 1,60 $\mathrm{m}$. El ancho del andén es estrecho, menor a los 5 $\mathrm{m}$. El largo es muy variable pero suele alcanzar decenas de metros. Son las construcciones que alcanzan los niveles más monumentales. Denomino "sistema de andenes" a aquellos andenes contiguos que se encuentran atravesados por los mismos canales de irrigación.

- Muro de contención de terreno: siguiendo a Albeck (1993), son aquellos muros construidos para la conservación de suelos y el control de la erosión. Sus dimensiones son muy variables. Pueden ubicarse adyacentes a la barranca de los ríos y arroyos; en forma transversal a los cauces manteniendo estable el nivel de base; o en sectores elevados sobre los terrenos agrícolas para contener los derrumbes. 
- Despedre: acumulaciones de piedras sobre la superficie del campo producto de la limpieza de los terrenos de cultivo. También denominados "ronques" o "caminos de cascajo" (Suetta, 1967).

- Estructura de almacenamiento: en el área se han identificado dos tipos de estructuras posiblemente vinculadas al almacenamiento de cosecha o herramientas. El primer tipo corresponde a las estructuras conocidas en la literatura andina como estructuras chullparias o chullpas (Nielsen, 2018), con dos subtipos presentes. Uno es el llamado torre-chullpa, estructuras de piedra de 1,5 m aproximadamente de alto, con planta circular y una abertura con dintel orientada al este (Pey, 2016); el otro corresponde a las cámaras elaboradas con barro y piedra y ubicadas sobre abrigos rocosos, similares a las descriptas por Debenedetti (1930). El segundo tipo, asociado al almacenamiento, se describe como pequeñas oquedades debajo de grandes bloques rocosos que, en algunas ocasiones, cuentan con un muro delimitador, similar al tipo "refugio" descripto por Quesada (2007) en Antofalla. En la actualidad, tanto las chullpas como los "refugios" se encuentran vaciados.

- Tumba: en general se presentan como estructuras de piedra bajo grandes bloques rocosos muy visibles en el paisaje y cercanas a los campos de cultivo. También pueden incluirse dentro de esta categoría las chullpas en alero debido a la versatilidad funcional que se le ha atribuido a este tipo de estructuras y las múltiples interpretaciones que se han realizado al respecto. Como sugiere Nielsen (2018) y también hemos expresado en otro trabajo (Pey y Carboni, 2018), la división entre categorías excluyentes como "sepulcro" y "depósito" no es más que un producto de nuestra lógica, pudiendo haber estado ambas funciones estrechamente vinculadas en el pasado.

- Trampa para zorro: estructura de piedra de un metro de alto, con base rectangular y que presenta una abertura o vano asociado a una laja que obstruye su entrada (Barón Parra, 2005, pp. 61-62; Vaquer y Cámera, 2018, p. 48).
En cuanto al sistema de irrigación, para su interpretación consideré la propuesta de Barceló (1996), también aplicada por Quesada $(2001,2007)$ y Díaz (2013). Barceló repara en la importancia de identificar un canal principal, es decir, aquel que haya brindado o brinde un mayor caudal de agua y del cual deriven canales secundarios que irriguen los terrenos. El canal principal marca una línea de rigidez, es decir, delimita el crecimiento del espacio de cultivo dependiente de su curso. Esto se debe a que la circulación del agua siempre va a estar determinada por la dirección de la pendiente y la gravedad. Todos aquellos componentes que se encuentren a una mayor altura respecto de la línea de rigidez no pudieron ser alimentados por este canal y, por lo tanto, quedan fuera de la red. En términos generales, en Cusi Cusi, las acequias pueden presentar uno o dos muros laterales o también pueden consistir en meros surcos cavados en la tierra. Estos últimos son aún más difíciles de identificar en el campo por lo que, en muchos casos, tan solo he podido registrar una parte de su recorrido. Por último, existen otros dos tipos de estructura que conforman la red de riego: las tomas de agua y los reservorios. Las primeras son rasgos por los que se desvía el agua desde los arroyos o vertientes naturales a la acequia principal; los segundos son estructuras amuradas y/o cavidades impermeabilizadas contenedoras de agua para su posterior canalización.

Otra de las tareas que realicé en el campo fue entrevistar a tres miembros de la familia Quispe respecto de la historia del sitio y las prácticas desarrolladas en él. Para ello me basé en el método etnográfico de entrevista no dirigida (Guber, 2001).

\section{En el laboratorio}

La segunda etapa se desarrolló en el laboratorio, en donde procesé los puntos tomados por la Estación Total mediante un Sistema de Información Geográfica $(\mathrm{SIG}) .^{2}$ Digitalicé cada estructura para finalmente obtener una capa vectorial con el plano del sitio y una base de datos geoespaciales con cada objeto discriminado por tipo y modo constructivo

2 El software que he empleado es el QGIS v3.4.3 (QGIS Development Team, 2019), disponible para su libre descarga en: https://qgis.org. 
identificado (ver más adelante). También digitalicé aquellos tramos de canales que fueron identificados y mapeados en el campo para elaborar un primer modelo de red de irrigación del sitio.

A su vez, apliqué una interpolación TIN (Triangulated Irregular Network) sobre los datos altimétricos discretos que obtuve en el relevamiento. El método de interpolación utiliza puntos vectoriales con valores conocidos para estimar valores en ubicaciones desconocidas con el fin de crear una superficie raster que cubra un área completa (en este caso, el sitio). En particular, la interpolación TIN utiliza puntos de muestra para crear una superficie formada por triángulos y basada en la información de los puntos vecinos más cercanos. De esta manera obtuve un modelo digital de elevaciones (MDE) a escala de sitio.

El MDE local me permitió dos cosas. Por una parte, elaborar dos capas de curvas de nivel (con intervalos de $5 \mathrm{~m} \mathrm{y} 2 \mathrm{~m}$ ) y, por otra, crear un mapa de costos de desplazamiento de acuerdo a las pendientes del terreno. Luego, sobre aquel mapa de costos ejecuté dos procesos. Primero, el r.cost, cuyo resultado es un mapa raster que muestra el costo acumulativo. Segundo, apliqué sobre dicho mapa el proceso r.drain. Este algoritmo traza un camino (o más) de menor costo acorde al nivel de dificultad que presente el terreno. Para ello es necesario seleccionar un punto de origen desde donde, hipotéticamente, partiría el flujo de agua. El objetivo de este método es predecir, a partir de un modelo matemático, cuál es la ruta naturalmente más sencilla para que discurra el agua en un terreno abrupto.

En cuanto a la información arquitectónica, fue convertida en una base de datos en Microsoft Access y luego analizada en búsqueda de patrones constructivos.

\section{Resultados: Huayatayoc, un sitio complejo}

\section{Las estructuras}

El sitio se compone por aproximadamente 55 terrazas de cultivo (distribuidas dentro de al menos 14 sectores delimitados por muros perimetrales), 31 andenes (17 distribuidos dentro de 3 canchones pircados y 14 organizados en un sistema sin muro perimetral en el sector D), 4 reservorios de agua circulares y un canal principal (Figura 4). A su vez, a metros del sector A, ladera arriba, se emplazan dos

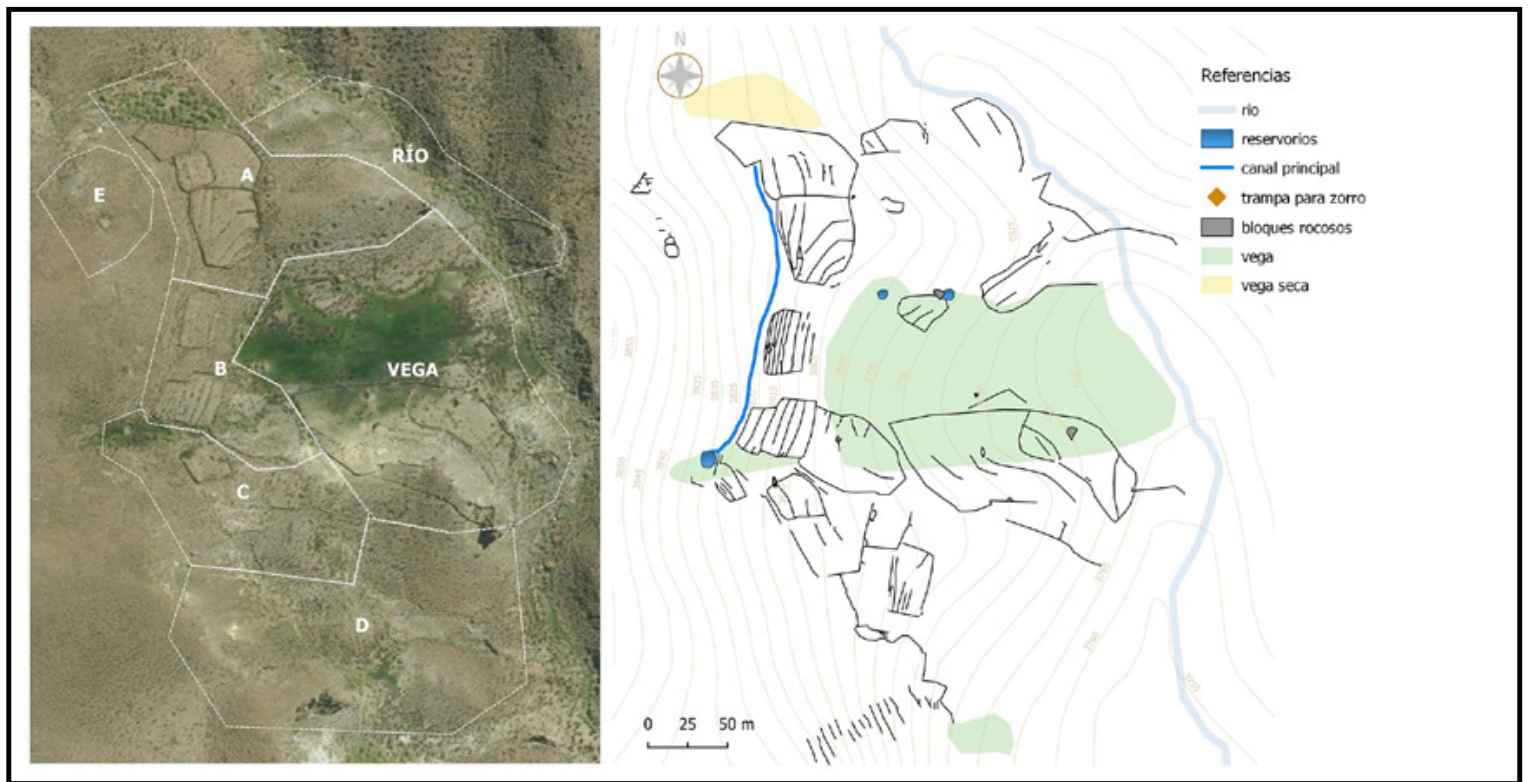

Figura 4. Huayatayoc Alto sectorizado -fuente de la imagen satelital Bing Maps Aerial (c) 2010 Microsoft Corporation(izquierda); plano de Huayatayoc Alto (derecha). 
corrales pequeños con un recinto rectangular adosado cada uno. También se destaca una trampa de zorro en unos de los accesos superiores principales del sitio. A $500 \mathrm{~m}$ de la vega principal y en dirección sur, se encuentra el puesto actual de la familia Quispe (uno de los tres que posee en las inmediaciones de Cusi). Cercano a este último se halla el único rasgo del paisaje que pude asociar con almacenaje, en este caso de herramientas. Se trata de una oquedad bajo un gran bloque errático de ignimbrita que presentaba en su interior una pala lítica de dacita en buen estado de conservación.

En el sector $\mathrm{C}$ registramos una plataforma de $3 \times 5$ $\mathrm{m}$ nivelada por un muro de $0,22 \mathrm{~m}$ de alto en cuya superficie se observan dos pilas de rocas medianas enfrentadas al vano de una pequeña estructura de $0,40 \mathrm{~m}$ de alto. Este tipo de estructura no se observó en los otros sitios agrícolas del área y fue difícil reconocer su tipo y/o funcionalidad en la bibliografía. Finalmente, en una de las entrevistas, fue identificada por R. Quispe como un sector donde se desarrollaban (dos generaciones atrás) actividades textiles, siendo ambas pilas sostenes para los parantes del telar y la estructura un asiento para el tejedor (R. Quispe, com. pers., 2 de mayo 2018) (Figura 5). A juzgar por la distancia entre los parantes y el asiento, el telar poseía una urdimbre de varios metros de largo (S. Desrosiers, com. pers., 15 de febrero 2019). Según el cuseño, la actividad textil de grandes piezas estaba reservada para su abuelo, es decir, para un miembro masculino de la familia. Mientras que los tejidos más pequeńos, realizados a mano y con agujas, estaban en manos de las mujeres.

En cuanto a la actividad agrícola, ¿qué se ha cultivado en estos andenes y terrazas? Si bien aún no he realizado sondeos en búsqueda de micro y macrorrestos vegetales, el relato oral brinda alguna información al respecto. Sus propietarios aseguran que hasta que se abandonó la actividad agrícola -hace aproximadamente 20 ańos- los diferentes tipos de cultivo se encontraban sectorizados. Lo último que se produjo fue papas y habas. Una generación atrás se cultivaba cebolla, zanahoria y papa y, previamente, producían también oca y quinua. A su vez, me han informado que hasta hace no muchos años todavía se criaban ovejas y, en la actualidad, el sitio está incorporado al sistema pastoril de la hacienda familiar de llamas. Respecto del cuidado de los animales, R. Quispe detalló que cuando él era niño su madre estaba al cuidado de las ovejas, mientras que su padre se encargaba de las llamas (R. Quispe, com. pers., 2 de mayo, 2018). Los pequeños corrales circulares que se ubican en el sector E del sitio estaban destinados al rebaño ovino, que lo ocupaba estacionalmente. También, en dos de las entrevistas se informa que, cuando aún se cultivaba, eran los hombres quienes se encargaban de las tareas agrícolas mientras que las mujeres eran las responsables de cuidar la hacienda (R. Quispe, com. pers., 2 de mayo 2018 y E. Quispe, com. pers., 30 de abril 2017). De este modo se combinaban ambas actividades $y$, muchas veces, en el mismo espacio productivo alrededor de la vega.

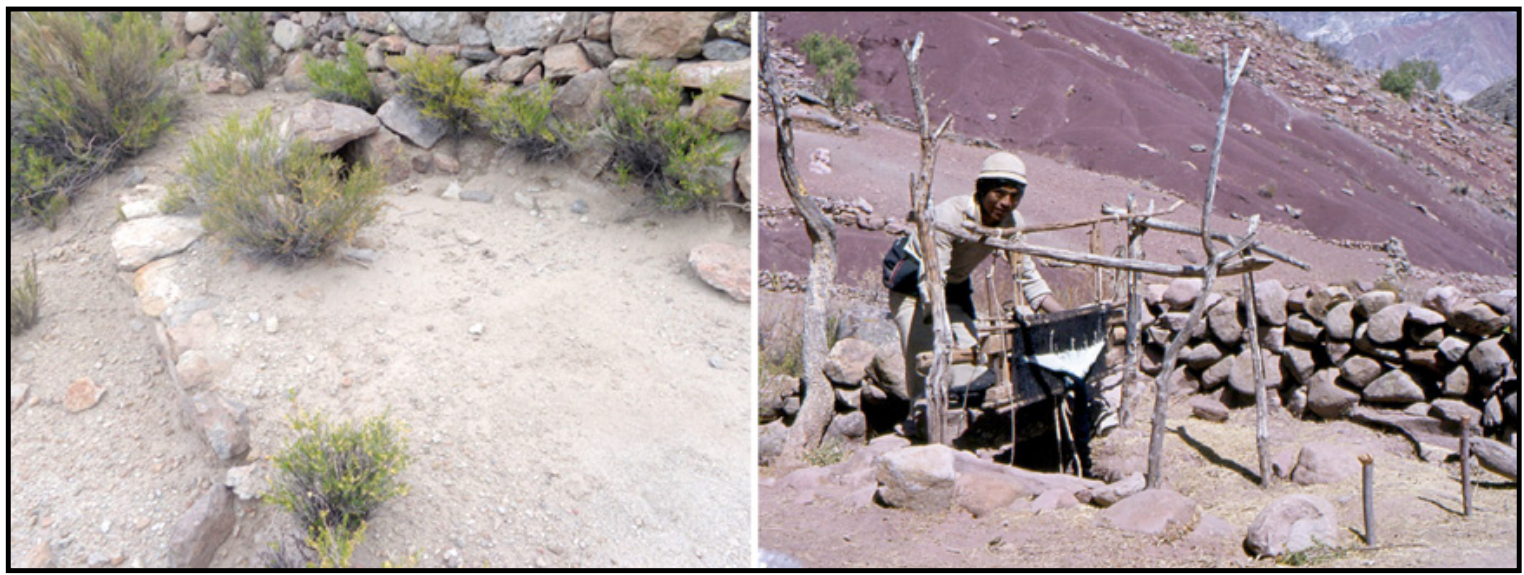

Figura 5. Estructura para tejer presente en el sector C de Huayatayoc (derecha); hombre tejiendo en el campo con un telar a pedal en Isluco (valle del Río Tomoyo, Potosí, Bolivia) en 1983. Fotografía gentileza de Sophie Desrosiers (@Desrosiers). 


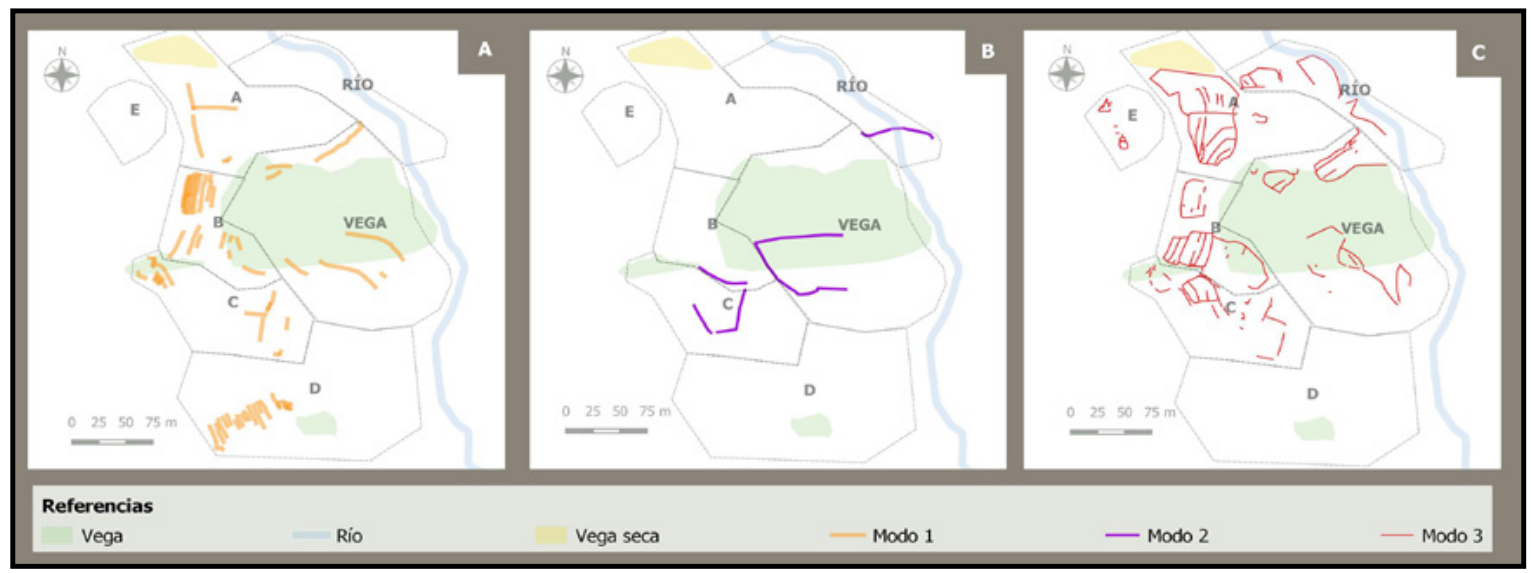

Figura 6. A. Distribución espacial de los muros construidos bajo el modo 1; B. Distribución espacial de los muros construidos bajo el modo 2; C. Distribución espacial de los muros construidos bajo el modo 3.

Respecto de la antigüedad del sitio, la familia Quispe afirma que este fue construido por "los abuelos" -familiares directos- sobre un "antigal" incluso más temprano del que todavía pueden apreciarse algunos pocos muros. A partir del análisis arquitectónico y de la secuencia constructiva, he logrado interpretar una historia ocupacional compleja y, posiblemente, con varios episodios de ocupación y reocupación en el tiempo. Los muros que conforman el sitio evidencian la fusión de sectores más antiguos con reparaciones o modificaciones sustanciales más modernas. Se han identificado tres técnicas o modos constructivos distintivos y que he correlacionado con momentos ocupacionales diferentes (Figura 6).

La técnica constructiva 1 (modo 1 ) se caracteriza por presentar muros de aparejo rústico, mortero entre sus rocas y la selección de rocas de un tamaño estandarizado (Figura 7). Su estado de conservación es notoriamente inferior respecto de los otros muros y en la mayoría de los casos se observa liquen tanto en su cara externa como interna. Su vista en planta revela dos hileras de rocas. Esta técnica se presenta tanto en muros de terrazas y andenes como en ciertos sectores de los pircados. En algunos muros se observa el empleo de rocas de mayor tamaño en los cimientos y la presencia de hornacinas en distintos estados de conservación. La altura, muy variable, registra elevaciones máximas de 2,18 m y mínimas de $0,50 \mathrm{~m}$. Suele combinarse con el modo 3, este último empleado a modo de restauración o completando tramos derrumbados. Es la técnica que predomina en los sectores $\mathrm{C}$ y $\mathrm{D}$, señalados por los actuales dueños como "antigales" dentro del sitio. También se presenta en varios andenes del sector B $y$, en menor medida, en los sectores A y Vega (Figura 6A). En los sectores A y B siempre se observa en los cimientos de los muros, donde es completada en su parte superior, a modo de reparación, por el modo 3 .

La técnica constructiva 2 (modo 2 ) se caracteriza por sus muros de aparejo rústico, la presencia de mortero entre sus rocas y un acabado muy prolijo (Figura 8). Si bien sus rocas no se encuentran trabajadas, se evidencia una selección de tamaños estandarizados que brindan cierta homogeneidad al conjunto. Se destaca la selección de caras planas para su exhibición. En planta, también se observan dos líneas de rocas. La altura de los muros está estandarizada y es de $1 \mathrm{~m}$. Esta técnica tan solo se presenta en los pircados de dos canchones presentes en el sector Vega; un muro del sector $\mathrm{B}$; un pircado del sector $\mathrm{C}$ y un lindero en el sector Río (Figura 6B). Esta modalidad no se combina con ninguna otra. Se trata de pircas que cercan grandes superficies y se destacan por su trazado rectilíneo. Sus muros poseen un mejor estado de conservación respecto del modo 1 . En algunos sectores, presentan ramas secas saliendo de entre las rocas de la parte superior del muro, probablemente con el objetivo de ahuyentar al ganado. Es posible que correspondan al momento de división intrafamiliar de parcelas que uno de los entrevistados ha narrado (E. Quispe, com. pers., 1 de mayo 2017). 


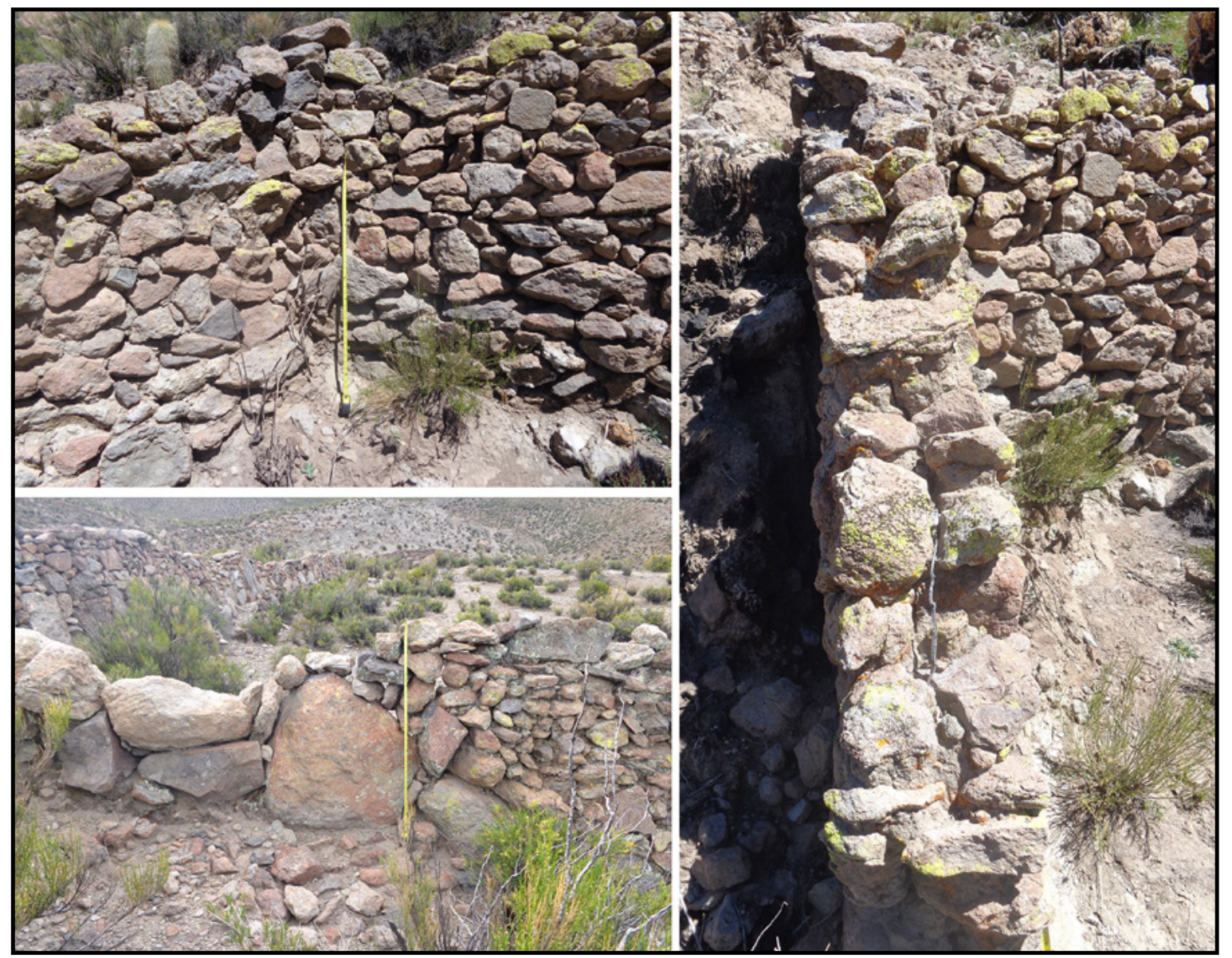

Figura 7. Vista frontal de un muro construido con la técnica o modo 1, escala $1 \mathrm{~m}$ (arriba); combinación de la técnica 1 con la 3 en el picardo del canchón CPH16, escala $1 \mathrm{~m}$ (abajo); detalle en el que se observan las dos hileras de roca que lo componen (derecha).

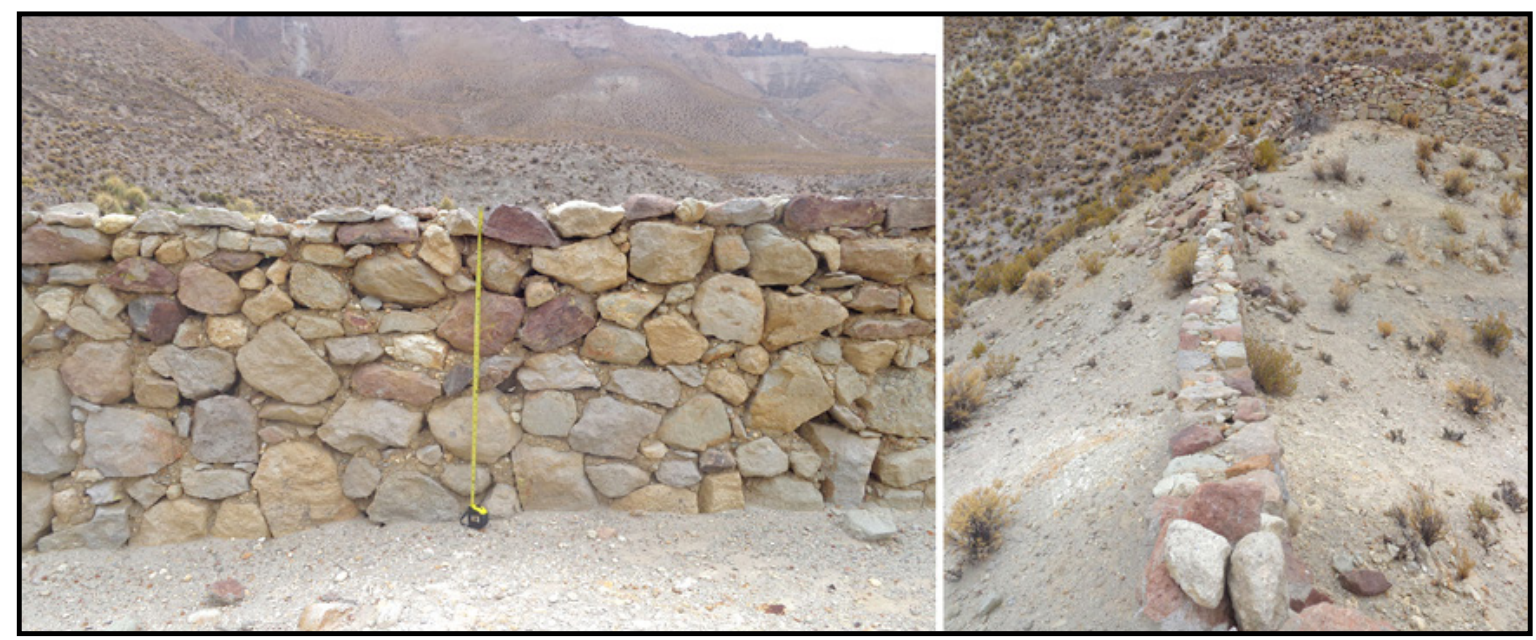

Figura 8. Vista frontal de un muro construido con la técnica o modo 1, escala $1 \mathrm{~m}$ (izquierda); detalle en el que se observan las dos líneas de roca que lo componen (derecha). 
De ser así, su función queda restringida a marcar una nueva división espacial y territorial en el paisaje respecto de momentos previos.

En cuanto a la técnica constructiva 3 (modo 3), su aspecto es mucho más rústico $\mathrm{y}$, de las tres, es la de manufactura más simple. Se emplean rocas sin trabajar y no se percibe un criterio de selección. Se basa en el apilamiento de rocas inmediatamente disponibles. El aparejo es rústico y se emplea piedra seca, es decir, sin mortero. En planta, se observa solo una línea de rocas (Figura 9). Suele combinarse con el modo 1, ya sea completando trayectos de pirca o restituyendo partes superiores derrumbadas. También se observan en los muros de corrales puestos abandonados, terrazas y en pequeños muros asociados al control de escorrentía. La altura es muy variable, registrándose máximas de $2,40 \mathrm{~m}$ a mínimas de $0,20 \mathrm{~m}$. Es el modo constructivo más versátil de los tres y el que se encuentra en mejor estado de conservación. Cabe destacar que en el sector $\mathrm{D}$ es donde se encuentra menos representado (Figura 6C).

Tras todo lo expuesto, es posible reconstruir -aunque sea tentativamente- una secuencia constructiva para Huayatayoc. Los muros más tempranos del sitio corresponderían a aquellos construidos bajo el modo 1 (Figura 10A). Más tarde los muros y terrazas antiguos (exceptuando los andenes del sector D) fueron reacondicionados y redefinidos con la técnica constructiva 3. Quiero destacar que la nueva estructuración del espacio productivo (que también incluyó la construcción de nuevos muros) se desarrolló sobre un espacio previamente definido por los muros del modo 1 (Figura 10B). Se ocuparon y reestructuraron viejos espacios productivos, mientras que el sector $\mathrm{D}$ fue prácticamente abandonado en lo que respecta a la práctica agrícola.

En algún momento de la historia familiar de sus propietarios, ocurrió una división de parcelas que se materializó en forma de largos pircados que fueron construidos empleando el modo constructivo 2 ( $\mathrm{Fi}$ gura 10C). En cuanto a la técnica 3, se siguió empleando en el tiempo para el mantenimiento de las terrazas y pircados hasta que se descontinuó la producción agrícola del área. Lamentablemente, con la información que poseo hasta el momento, es difícil determinar qué segmentos de muro del modo 3 fueron anteriores o posteriores a la división de parcelas. Hoy en día el sitio se presenta como un conjunto superpuesto de muros y reparaciones, tal como demuestra la Figura 10C.

\section{El riego}

Una de las características más importantes del sitio es su verdor y humedad. Esto se debe a que está emplazado sobre una gran vega alimentada por una serie de canales que se desprenden de ojos de agua o

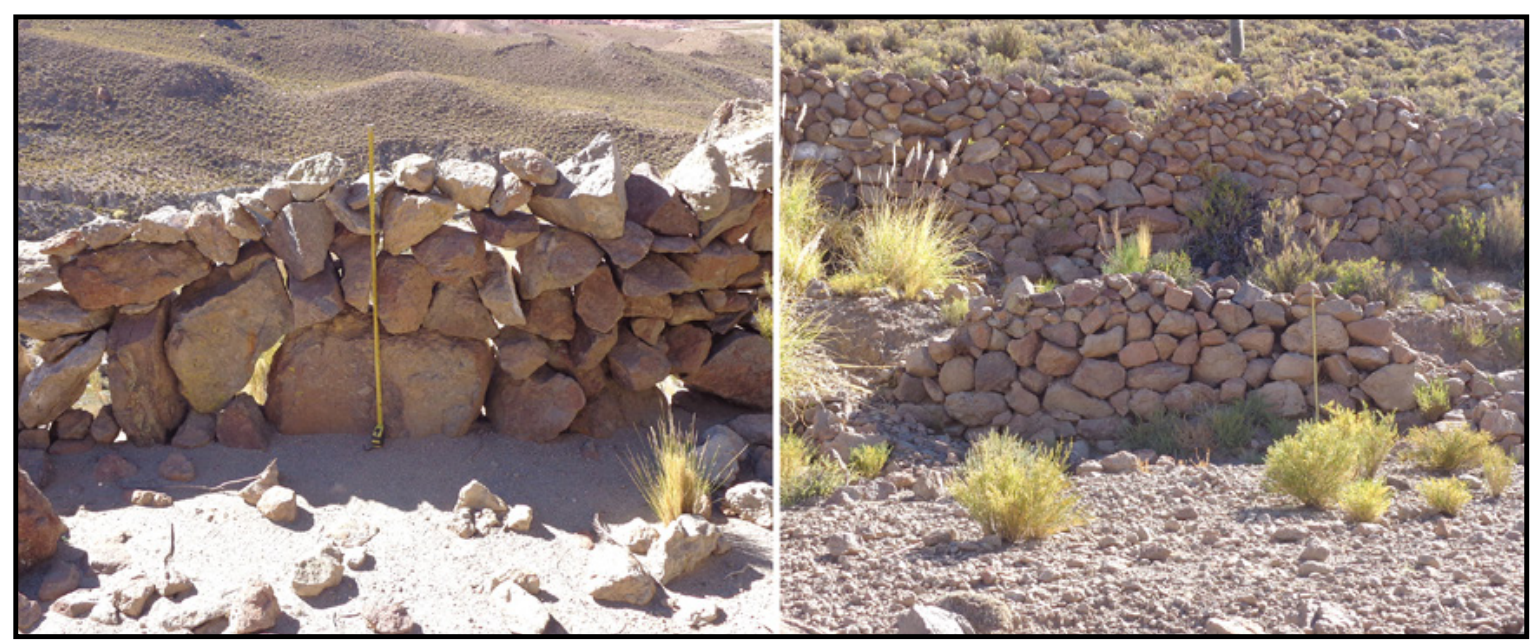

Figura 9. Vista frontal de un muro construido con la técnica o modo 3, escala $1 \mathrm{~m}$ (izquierda); empleo del modo 3 en la construcción de un picardo y una terraza, escala $1 \mathrm{~m}$ (derecha). 


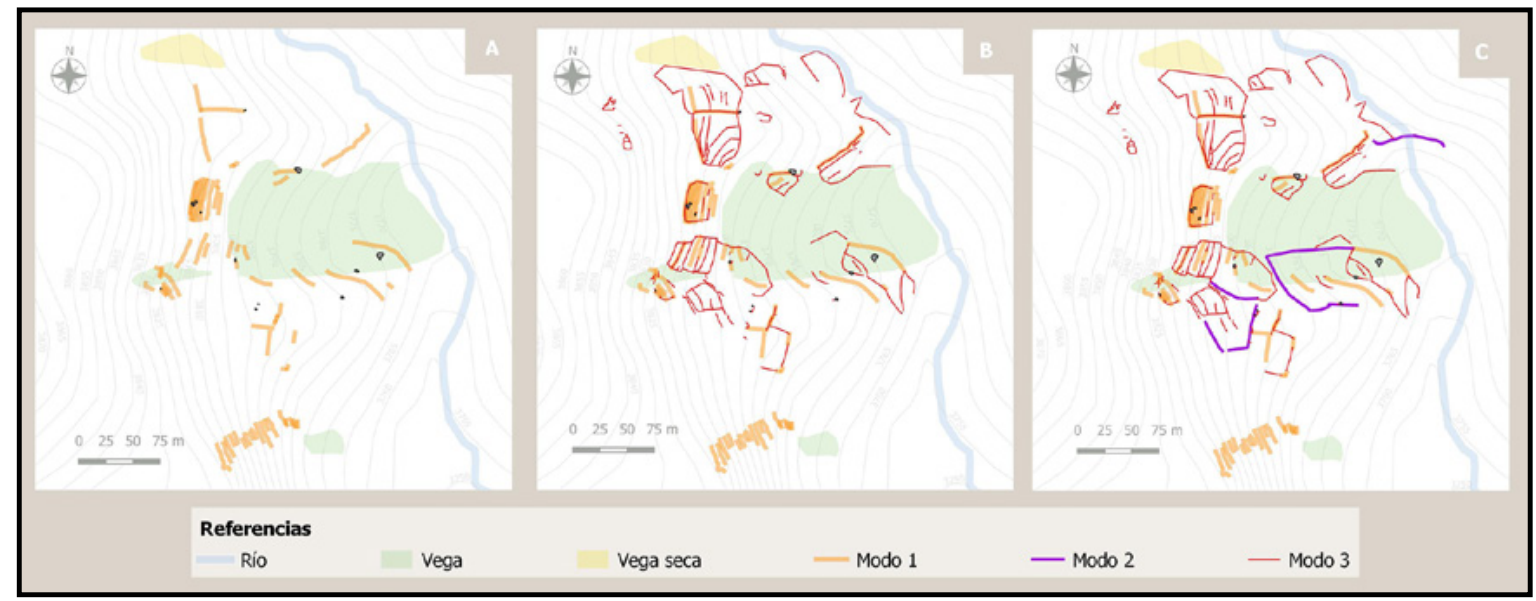

Figura 10. A. Evidencia de la primera etapa constructiva del sitio 1; B. Muros construidos bajo el modo constructivo 3 sobre las bases del modo 1; C. Superposición de técnicas constructivas en la actualidad incluyendo los linderos del modo 2.

manantiales nutridos por aguas subterráneas (Figura 11). Dicha alimentación no se desarrolla de manera natural, sino que es sostenida por un elaborado sistema de riego que ha sido mantenido en el tiempo. Los manantiales que la alimentan se encuentran contenidos por muros de barro y roca que actúan como tomas de agua. $\mathrm{Al}$ mismo tiempo, estas estructuras facilitan el almacenamiento del agua surgente actuando como verdaderos reservorios. En las entrevistas se menciona la existencia de cuatro ojos de agua de los cuales solo he podido identificar tres (RH1, $\mathrm{RH} 2$ y RH3). Es posible que el cuarto esté relacionado espacialmente con la vega seca del sector A.

Según la clasificación que emplea Díaz (2010), el principal sistema de irrigación del sitio posee un patrón ramificado. Se ha identificado un canal principal que corre en altura, posee un muro lateral y nutre a los sectores A, B, C, D y parte del sector Vega. Este canal se desprende del reservorio RH1, emplazado a 3825 msnm (Figura 11A). De dicho cauce principal se desprenden una multiplicidad de acequias secundarias (muchas de las que presen$\tan$ muros laterales y/o entradas formalizadas en los muros de los pircados) y surcos tanto en tierra como en vega (Figura 11C y D). Estos últimos son guiados con muros de champa, es decir, terrones de pasto y raíces que en terrenos como las vegas son más resistentes que las rocas (Palacios Ríos, 1988). Los canales de champa solo se emplean para la irrigación de las vegas.
Para elaborar el modelo de costos de flujo, planteé como punto de partida el RH1. Como resultado obtuve una ruta natural de escorrentía pendiente abajo en dirección W-E directo al río (Figura 12, derecha). Esta ruta coincide parcialmente con uno de los canales actualmente activos para alimentar la gran vega. Por el contrario, como puede observarse en la Figura 12 (izquierda), el sendero que marca el modelo difiere significativamente de la ruta y dirección del canal principal (en dirección S-N). Interpreto entonces el curso del canal principal como una desviación intencional del flujo natural que se desprende de la vertiente. Como mencioné anteriormente, para su ejecución y control se observa que se ha construido un muro lateral que recorre gran parte del camino del canal (Figura 11C).

En cuanto a los dos reservorios restantes, estos alimentan al resto de las terrazas del sector Vega que poseen inmediatamente al lado y a la vega propiamente dicha (Figura 12). Cada uno conforma un sistema de riego independiente y de mucha menor escala respecto del sistema principal. En la Figura 12 se distinguen aquellos canales que solo alimentan las vegas de aquellos que se conectan con sectores para el cultivo dentro de las estructuras agrícolas del sitio. Se pudieron rastrear gran parte de los canales que alimentaron dichas estructuras con dos salvedades: los andenes del sector D y los canchones pircados del sector Río. Si bien no se ha podido observar su conexión con la red de irrigación mayor, el hecho 


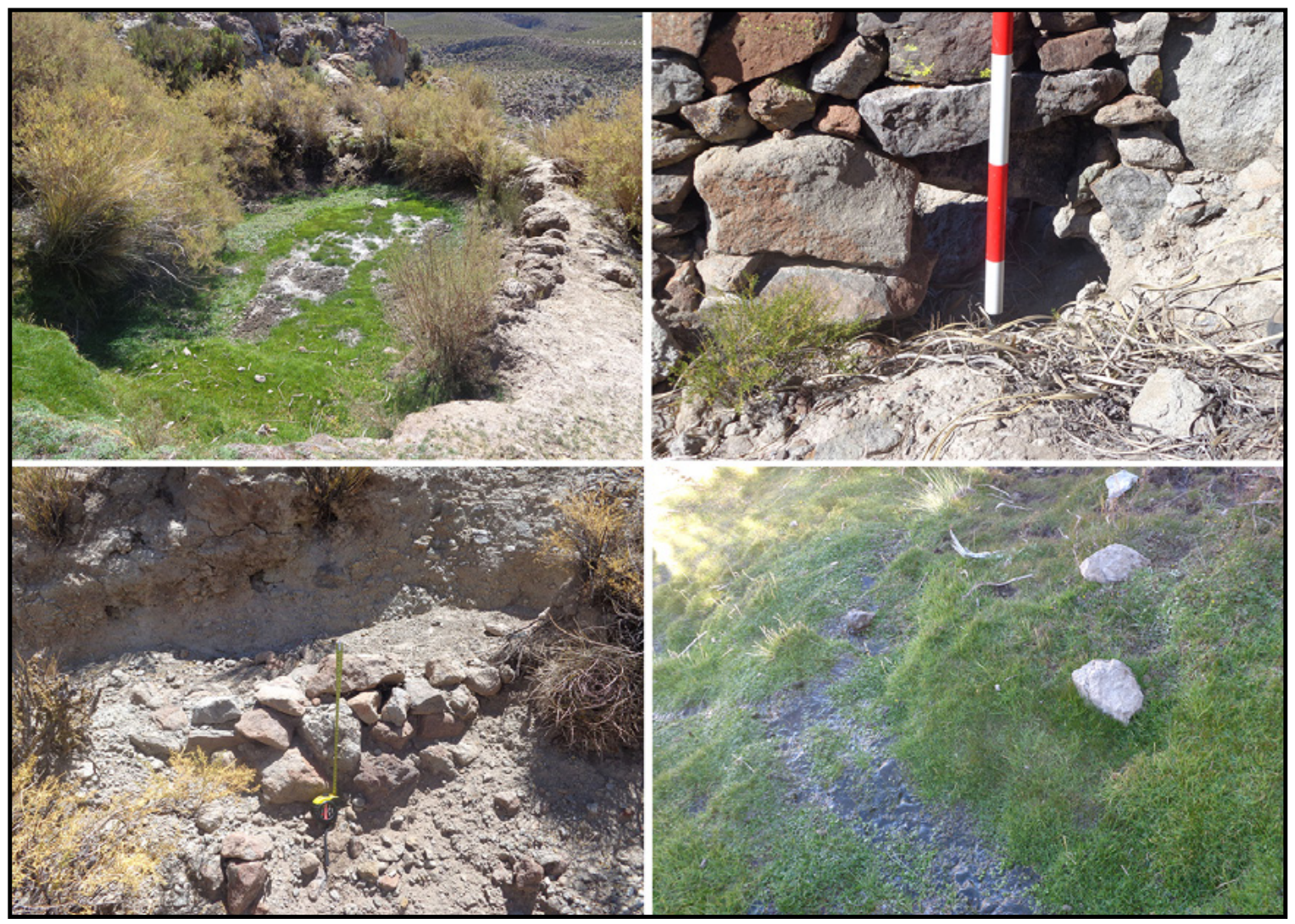

Figura 11. A. Reservorio RH1; B. Entrada formal de agua en pircado de canchón; C. Muro lateral de canal principal, escala $0,5 \mathrm{~m}$; D. Surco de irrigación sobre vega guiado por muros de champa.

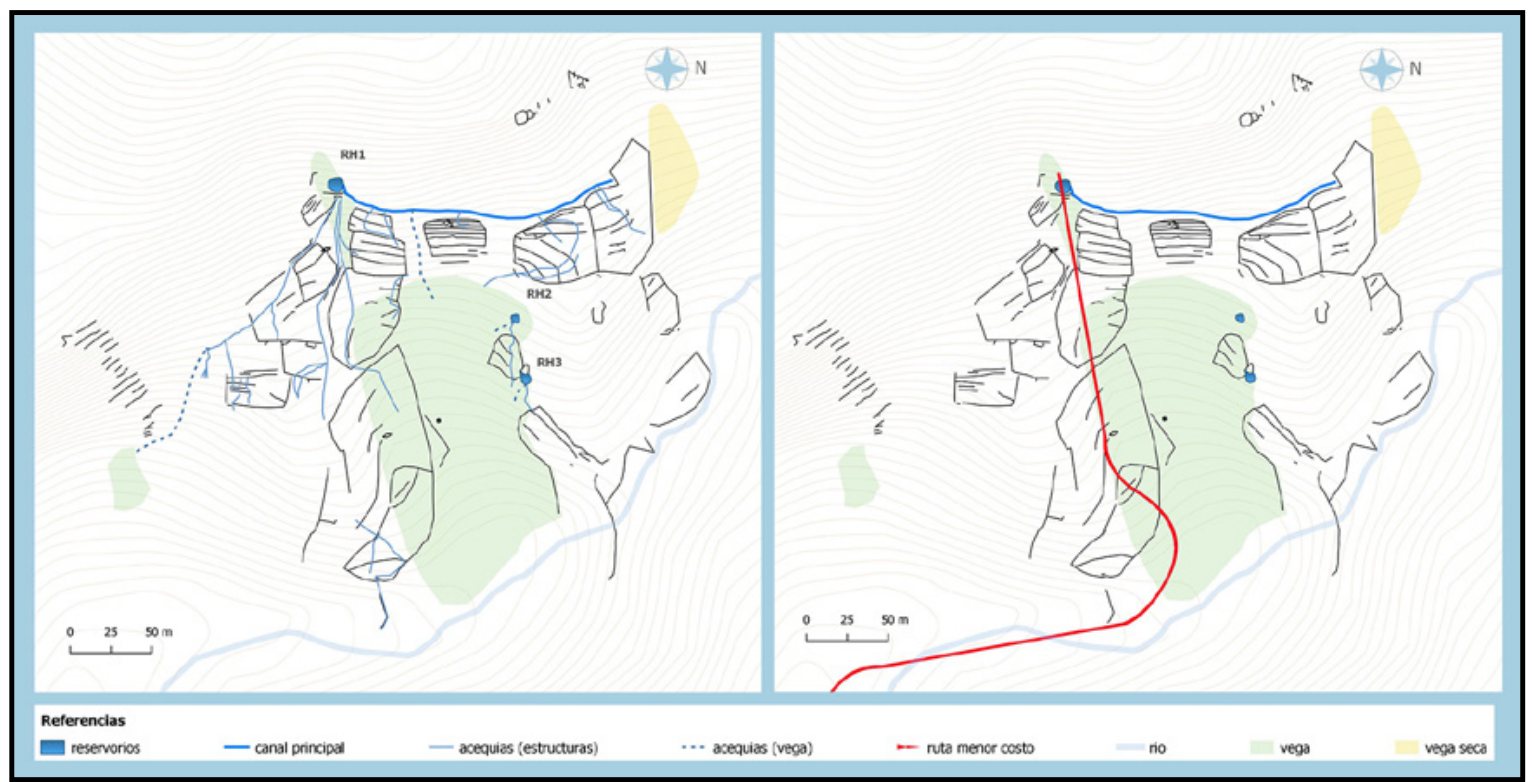

Figura 12. Sistemas de riego que se desprenden de las vertientes RH1, RH2 y RH3 (izquierda); ruta de menor costo para el flujo de agua proyectada por el modelo de SIG (derecha). 


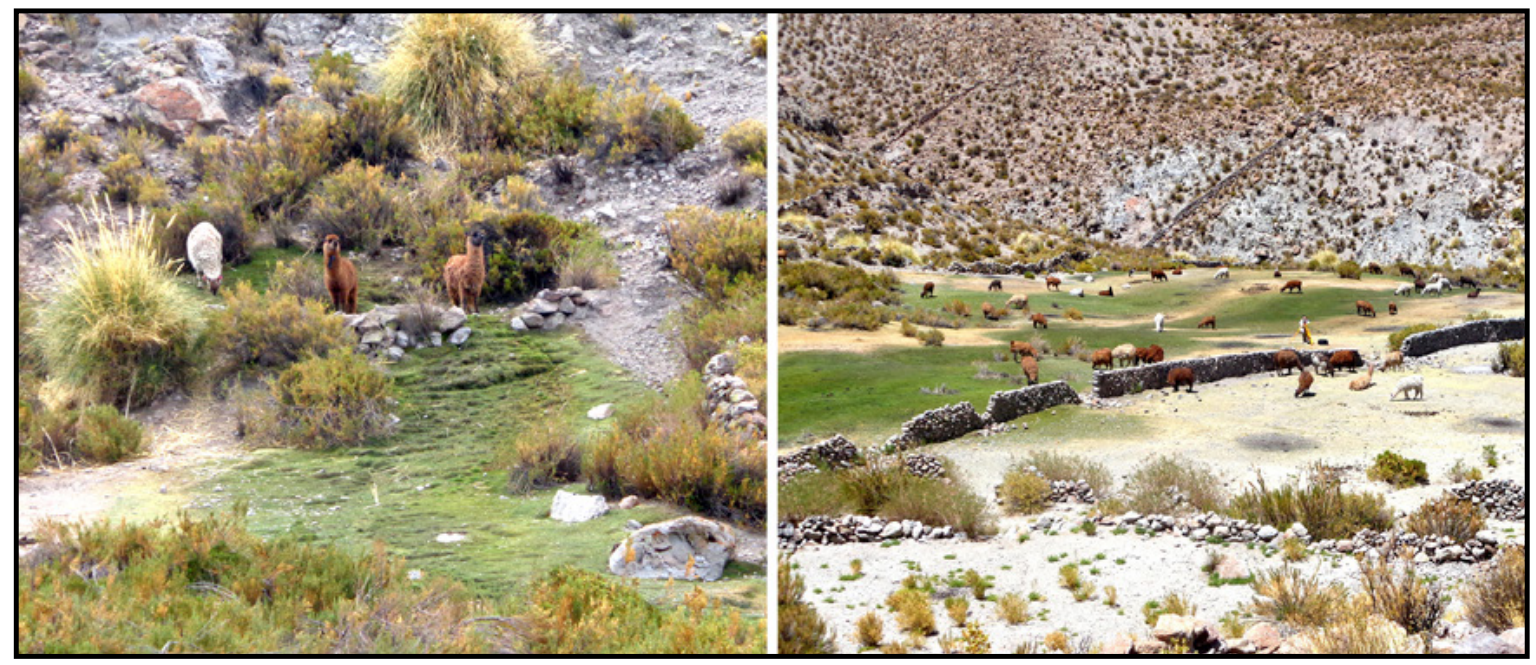

Figura 13. Llamas pastando y bebiendo dentro del RH2 (izquierda); vista general de la vega central con la hacienda pastando (derecha).

de que se encuentren en una cota altitudinal menor respecto del canal principal mantiene la posibilidad de que hayan sido irrigados por el agua proveniente del RH1. Sin embargo, en el caso de los andenes del sector $\mathrm{D}$, construidos enteramente bajo el modo 1 , con alto grado de deterioro y sin presentar reparaciones visibles, no descarto la posibilidad de que, por su antigüedad, hayan sido irrigados empleando un sistema del cual no se ha conservado evidencia. En el mismo sector, por debajo de este sistema de andenes, se halla una pequeña vega. Esta sí se encuentra conectada al sistema de riego del RH1 a través de una serie de canales y es probable que quizá, en tiempos en los que esa parte de la red estuviese activa, haya alcanzado mayores dimensiones.

E. Quispe afirma que hace más de 20 años que no se cultiva en estas terrazas por falta de mano de obra. Esta última ocasionada tanto por el fallecimiento de los mayores como por la migración y desinterés por parte de los más jóvenes (E. Quispe, com. pers., 30 de abril 2017). El desmoronamiento de muchos de los muros de control de escorrentía y la sequedad de los canales que llegan a las estructuras de cultivo dan cuenta de ello. Si bien uno podría suponer que en la actualidad, entonces, todo el sistema de riego se encuentra en desuso, esto no es así. Los tres reservorios siguen activos y los canales que riegan la vega principal continúan en constante uso y mantenimiento. Todos los veranos se reúnen las llamas de la hacienda familiar a pastar y a beber de las aguas y verdes pastos de Huayatayoc (Figura 13). Año tras año esta vega -o "ciénego", como le llaman- es nutrida y estimulada por el padre de familia, ya que reconoce el valor que posee este tipo de oasis en un ambiente como la Puna Seca.

\section{Agricultura de vega}

La crianza artificial de vegas en términos de forraje para el ganado no es algo novedoso y ya ha sido documentada en numerosos trabajos (Palacios Ríos, 1977, 1988; Merlino y Rabey, 1978; Haber, 1991, 1992, 2006; García, Rolandi, López y Valeri, 2002; García, Rolandi, Valeri y López, 2004; Lane, 2006a, 2006b, 2010; Quesada, 2007, entre otros). Esta práctica es aquella que Quesada y Lema denominan "agricultura de vega" y, si bien no se conoce su origen, "puede ser muy antigua pues podría haber sido estimulada por la práctica del pastoreo de camélidos desde el Período Arcaico (10.000-1000 AP)" (Quesada y Lema, 2007, p. 7). ${ }^{3}$ Es la crianza de las pasturas naturales que se desarrollan en los lugares muy húmedos derivando en la creación de un ambiente

3 La antigüedad prehispánica de esta práctica incluso fue reconocida por Guaman Poma de Ayala al mencionar que, en el pasado, los indígenas "todas las dichas acequias, agua de regar las dichas sementeras, hasta los pastos de ganado regaban en los altos y quebradas" (1993 [1615], p. 780, en Lane, 2010, p. 185). 
completamente artificial. No solo tiene como fin la extensión de la superficie de pastura, sino también apresurar su renovación una vez pasado el invierno.

En la Puna de Atacama, por ejemplo, estos espacios son conocidos desde el siglo XVIII como "potreros", y en las fuentes documentales se los caracteriza como formas productivas de baja inversión de trabajo en infraestructura -en contraste con las chacras agrícolas y sus tecnologías de riego (Quesada y Lema, 2011)-. Sin embargo, esta estrategia pastoril no es una tarea sencilla y sí requiere una alta inversión de trabajo para la construcción de las obras de riego. Se necesita diseñar e implementar un sistema que garantice un riego permanente y abundante para conseguir inundar grandes superficies de tierra (ver Quesada, 2007 para una descripción pormenorizada del funcionamiento de uno de estos sistemas de irrigación).

Palacios Ríos (1977) registró una interesante narración de un pastor aymara del departamento de Puno (Perú) respecto de los conocimientos que se requieren para extender y/o crear un bofedal. Se pueden crear bofedales a partir de la inundación permanente de un pajonal de Festuca sp hasta que este se pudra, actúe como abono y de allí surjan las especies hidrófitas. Este proceso puede demorarse de dos a cuatro ańos. Pueden diseñarse represas como reserva de agua y desde donde partan los canales, como observamos en Huayatayoc. Según el pastor aymara, si se mantiene el humedal puede durar mucho tiempo. De hecho, comenta que en su comunidad "hay canales que son muy grandes y tienen bastante antigüedad, han sido hechos por los abuelos, nadie sabe desde cuando están” (Palacios Ríos, 1977, p. 162) y que lo único que hacen ahora "es agrandarlos, haciendo irpas [canales] que pasen por las partes altas de la ladera y que inunden más grandes pampas" (Palacios Ríos, 1977, p. 161).

Este dato es sugerente al momento de contemplar la temporalidad de los reservorios de agua de Huayatayoc. En una de las entrevistas, al consultar por la edad de los "tanques" o "represas", R. Quispe comentó que efectivamente son antiguas -al menos del tiempo de "los abuelos"- y que requieren mantenimiento. Él intentó alguna vez hacerlo pero confiesa que "arruinó un tanque" porque no sabía bien cómo hacer para retener el agua, que antes "sabían sellar bien con barro arcilloso las fisuras" para que no permee el agua (R. Quispe, com. pers., 2 de mayo 2018). Hoy en día es su padre quien mantiene las represas y hace las desviaciones o acequias para criar la vega. Ocurre que, al expandirse, el humedal va sepultando estas canalizaciones. Por ello, en muchos casos, las obras destinadas al riego de vega son poco visibles. Esto dificulta la visualización de los sistemas de riego arqueológicos que no han sido mantenidos en el tiempo.

Sin duda, establecer una agricultura de vega requiere poseer destreza técnica. Para decidir el tipo de trazado que se implementará en la construcción de un canal -recto, curvo o en zigzag-, se debe tener en cuenta la dirección y el grado de pendiente del suelo. Siguiendo el relato recopilado por Palacios Ríos (1977), es muy importante que nunca falte el agua ya que de ocurrir, se comienzan a quemar las plantas desde la raíz y pueden tardar más de 14 años en rebrotar. Al igual que registré en Huayatayoc, todos los canales que irrigan las vegas en aquella comunidad aymara tienen revestimiento de champa. Por ello, después de las lluvias, se acumula sedimento y hay que limpiarlos. Ese mismo sedimento sirve luego para engrosar y mantener las paredes del canal. Otra de las tareas que se requiere es la quema periódica para renovación del pastizal (Palacios Ríos, 1977).

En todas estas actividades consiste la crianza de los humedales en la puna. En este caso, criar implicaría "cultivo, protección, aliento, amparo" (Rengifo Vásquez, 1999, p. 132, en Lema, 2014), a lo que sumaría la acumulación de trabajo campesino en el tiempo. Al considerarse espacios productivos muy preciados, los padres suelen heredarle la mejor parte al hijo o hija menor en reconocimiento al cuidado que él o ella les haya prodigado en la vejez (García et al., 2002, 2004). Es así como las vegas se siguen alimentando, creciendo o manteniéndose a lo largo de los años y generaciones, muchas veces, dentro de la misma familia. Retomando la mirada hermenéutica, en Huayatayoc, las prácticas de irrigación del pasado han dejado su huella material en forma de reservorios y canales que han sido reinterpretados en las prácticas actuales en función del desarrollo de una verdadera agricultura de vega. Una relación recursiva en la que habitar este paisaje no solo implica 
modelar el entorno (a través de la quema, el abono o la creación de canales de champa), sino también ser guiado y modelado por las marcas materiales de prácticas previas. $\mathrm{Y}$, estas prácticas, pudieron ser parte de lógicas distintas a las que hoy en día se desarrollan.

\section{Discusión}

\section{Un asunto de lógicas, pero ¡cuáles?}

En la microrregión de Cusi Cusi, hasta el momento, sitios de la envergadura de Huayatayoc habían sido entendidos desde una perspectiva meramente agrícola. Sin embargo, el actual uso que se le brinda al sistema de irrigación de este sitio nos señala las limitaciones del modelo actual para interpretar la biografía del paisaje local. En el planeamiento y configuración de este espacio productivo no solo operó un habitar guiado por la producción de alimentos vegetales, sino que también intervino una lógica centrada en las necesidades de criar camélidos y ovejas. Una lógica en la que lo que se busca irrigar, cultivar y extender es la pastura natural de la vega. Por lo tanto, es necesario comenzar a considerar la coexistencia espacial de elementos que remitan a ambos modos de concebir y estructurar el paisaje.

Asimismo, considero que dicha coexistencia no solo pudo darse en términos restrictivamente espaciales sino también temporales. Si incorporamos al modelo interpretativo la posibilidad de una tercera lógica, la agropastoril, podemos pensar en prácticas mixtas en un mismo tiempo y espacio. Huayatayoc se emplaza en un sector intermedio entre el límite de altura máximo para la agricultura y uno de los pisos más bajos contemplados por el sistema pastoril andino. Retomando lo planteado por Lane (2006a), se trata del escenario ideal para la implementación de un sistema agropastoril. Asimismo, este tipo de lógica permite a los agentes variar la intensidad que se le brinda a una u otra actividad según las características coyunturales. De hecho, los relatos orales sobre Huayatayoc cuentan que, hasta hace no mucho tiempo, se desarrollaron actividades mixtas a partir de una división del trabajo: los hombres en la chacra, las mujeres con la hacienda. Con el tiempo, la falta de mano de obra derivó en la adopción de un modelo meramente pastoril.

Teniendo en consideración lo anterior, planteo dos hipótesis para interpretar la historia ocupacional del sitio; ambas posibles pero excluyentes entre sí. La primera postula que el sitio fue pensado inicialmente desde una lógica agropastoril en la que la crianza de la vega se alternara con las prácticas agrícolas en un sistema de complementariedad. En ese caso es posible que el énfasis en el riego de las terrazas y de la vega se haya intercalado de manera estacional o por períodos acordes a las necesidades del ganado y el cultivo. Incluso es posible que, mediante la activación de todos los reservorios y canales derivados, pudieran haberse mantenido ambos sistemas. Si se tiene en cuenta la pequeña vega con evidencia de irrigación que se halla en el sector $\mathrm{D}$, también es factible que la superficie ocupada por humedales haya alcanzado mayores dimensiones. Esta pudo haber formado parte del sistema de pasturas, así como también haber participado en la irrigación de una serie de antiguas terrazas que se hallan -en muy mala conservación por el desuso y que no han podido ser mapeadas- pendiente abajo.

Si esto fuera así, sería esperable que los pircados que encierran tanto los sistemas de terrazas como los de andenería daten desde el origen de las estructuras (al menos su trazado original). Tal como se ha registrado en el área de Casabindo para tiempos formativos, cuando los animales y el cultivo se criaban en los mismos espacios y los vegetales debían ser resguardados de la hacienda (Albeck, 2011). Esta expectativa se condice con el hecho de que ciertos sectores de los muros perimetrales corresponden a la técnica constructiva o modo 1 ; por ejemplo, una esquina de canchón dentro del sector $\mathrm{C}$.

La segunda hipótesis supone que el sitio, en su origen, fue planeado exclusivamente para la actividad agrícola, focalizando el esfuerzo en el mantenimiento de las terrazas o andenes y las tareas agrícolas. Luego, a lo largo del tiempo fue reocupado desde una lógica agropastoril que diversificó el trabajo y realizó ciertas modificaciones en las redes de riego y las estructuras agrícolas con el fin de convertir un sector del sitio en abrevadero y pastura para los animales. Muchas de las terrazas fueron abandonadas 
y con el tiempo se deterioraron, mientras que otras fueron mantenidas con modificaciones visiblemente contrastantes. En cuanto a los pircados, se establecieron nuevos trazados y en algunos sectores, se repararon los antiguos incrementando la altura de sus muros como protección frente a los animales. Un ejemplo de ello serían los muros del modo 1 de uno de los canchones pircados del sector A, cuya parte superior se encuentra restaurada con rocas secas del modo 3. Finalmente, ambas hipótesis contemplan el abandono paulatino de las prácticas agropastoriles derivando en una agricultura de vega destinada exclusivamente a la cría de llamas. Solo algunas partes de la red de riego se encuentran activas, principalmente las que desembocan en la gran vega central.

Trasladándonos a una escala microrregional, el escenario propuesto por la segunda hipótesis es similar al que se ha planteado para el sitio Casas Quemadas. En su ocupación inicial, este presenta un fuerte componente agrícola con un énfasis en la construcción e irrigación de áreas de cultivo y en la elaboración y reactivación de palas líticas (Pey y Bonelli, 2016). Luego, se registra un abandono de las estructuras de cultivo y una posterior reutilización de ellas a manera de corrales de camélidos, pero, en este caso, en el marco del tráfico caravanero colonial (Vaquer, 2016).

\section{Huyatayoc, más que un palimpsesto}

Tello (1999) propone entender el paisaje agrícola como un palimpsesto. Plantea que cada grupo de agricultores (y/o pastores) va dejando una huella territorial y tecnológica distintiva en el paisaje, el que ya carga con los rastros de aquellos que los precedieron. Dichas marcas, al mismo tiempo, condicionan y canalizan los movimientos y las actividades de las generaciones posteriores. El concepto de palimpsesto de actividades no es novedoso en arqueología (ver Bailey, 2007) y podría aplicar muy bien para interpretar la compleja biografía de Huayatayoc. De hecho, se encuentra en sintonía con la idea de recursividad antes desarrollada. Sin embargo, aquí me interesa comenzar a explorar otra analogía. La que surge a partir de la consideración e incorporación de una de las prácticas que también tuvo lugar en el sitio y acompańó cada una de estas actividades: la textil. Como postula Ingold: "Los seres humanos, en sus movimientos, no inscriben sus historias de vida sobre la superficie de la naturaleza como lo hacen los escritores sobre una página, sino más bien, tejen dichas historias a la par del ciclo de vida de plantas y animales, en la textura misma de aquella superficie" (Ingold, 2000, p. 198, traducción mía).

En este sentido, propongo entender el paisaje local, más que como un palimpsesto, como un entramado de lógicas que se sucede en el tiempo. Un tejido en el que los reservorios no solo actúan como contenedores de agua, sino también como reservorios de experiencias vividas. Con el correr del tiempo, en Huayatayoc, los antiguos muros actuaron como la urdimbre sobre la que se fueron entrelazando nuevas formas de concebir el espacio y la actividad productiva. Algunos de estos hilos tienen forma de canales que, según la lógica que guíe su trazado, van cambiando el dibujo de la pieza. En algún momento, en esta puede predominar el morado de la quinua mientras que, en otro, el fuerte verdor de los pastos de la vega. Cuando de lana se trata, puede ser de llama pero, según los tiempos que corran, también de oveja. Algunas veces, el paisaje es tejido con la cadencia de las agujas de las mujeres que cuidan su hacienda y otras, al ritmo del telar de los hombres junto a la chacra. Finalmente, debemos tener en cuenta que, como arqueólogos y arqueólogas, accedemos a tejidos que -lejos de estar acabados- siguen tejiéndose con los movimientos de quienes aún los habitan y recorren.

\section{Conclusiones}

$\mathrm{Al}$ inicio de este trabajo me preguntaba hasta qué punto las lógicas pastoril y agrícola corren por caminos paralelos o excluyentes en el paisaje de Cusi Cusi. El caso de Huayatayoc demuestra que, muchas veces, estas convergen en los mismos espacios. Este encuentro se da a partir de la recuperación y resignificación de elementos previos que remiten no solo a otras temporalidades sino también a otras formas de habitar y configurar el paisaje. Es así como antiguos andenes de cultivo son ahora parte del sistema de pastoreo de una tropilla de llamas o, incluso, objeto de estudio de un equipo de arqueólogo/as -la sexta lógica identificada por Vaquer y Cámera (2018)-. 
En un ambiente donde lo que convoca es el agua, no resulta extraño que convergieran en el mismo espacio cultivos y animales, agricultores y pastores. El estudio de la biografía de sitios como este también requiere considerar la posibilidad de una lógica agropastoril. En el área, esto nos permitirá una mejor interpretación de aquellos sitios donde las actividades de pastoreo y agricultura de vegetales para consumo humano se dieron de manera sincrónica. En este caso, la consideración de la lógica agropastoril me ha permitido desarrollar al menos dos hipótesis para la interpretación del historial ocupacional de este locus de encuentro. Si bien ambas aún requieren ser afinadas y contrastadas ante futuros análisis, son un primer paso hacia una comprensión integral de las dinámicas del paisaje agrario local.

Para finalizar, el desarrollo de este trabajo invita a explorar otras formas de interpretar el modo en el que las distintas lógicas -construidas a partir del ejercicio de la hermenéutica- pueden relacionarse en el tiempo y el espacio. Se comienza a "hilar" así una analogía textil que requiere una mayor profundización a futuro y que promete brindar una alternativa viable frente al clásico palimpsesto arqueológico.

\section{Agradecimientos}

Agradezco a la familia Quispe de Cusi Cusi por su tiempo y sobre todo por brindarme el acceso a su campo y a su historia familiar. Al Dr. Hugo Yacobaccio, al Dr. José María Vaquer y al Dr. Kevin Lane por sus valiosos aportes sobre el manuscrito. También quiero expresar mi agradecimiento a las y los evaluadores cuyas observaciones y sugerencias han enriquecido este trabajo. Y finalmente, a las y los integrantes del equipo del Proyecto Arqueológico y Antropológico Pallqa, sin quienes el relevamiento de campo no hubiese sido posible.

\section{Referencias citadas}

Albeck, M. E. (1993). Contribución al estudio de los sistemas agrícolas prehispánicos de Casabindo (Puna de Jujuy) (Tesis doctoral). Facultad de Ciencias Naturales y Museo, Universidad Nacional de La Plata, La Plata, Argentina.
Albeck, M. E. (2011). Estudios de agricultura prehispánica en Casabindo (1980-1993). En Korstanje, M. A. y Quesada, M. (Eds.). Arqueología de la Agricultura. Casos de estudio en la región andina argentina (pp.12-47). San Miguel de Tucumán, Argentina: Ediciones Magna.

Bailey, G. (2007). Time perspectives, palimpsests and the archaeology of time. Journal of Anthropological Archaeo$\log y, 26,198-223$.

Barceló, M. (1996). El diseño de los espacios irrigados en al-Andalus: un enunciado de principios generales. En Barceló, M., Kirchner, H. y Navarro, C. (Eds.). El agua que no duerme. Fundamentos de la arqueología hidráulica andalusi (pp. 49-71). Granada, Espańa: Sierra Nevada 95/El legado andalusí.

Barón Parra, A. M. (2005). Huellas en el desierto. Patrimonio Cultural en la Zona del Proyecto Alma. Santiago: Printas impresores.

Barrett, J. (1999). The Mythical Landscapes of the British Iron Age. En Ashmore, W. y Knapp, B. (Eds.). Archaeologies of Landscape. Contemporary Perspectives (pp. 253265). Oxford: Blackwell Publishers.

Browman, D. L. (1990). High altitude camelid pastoralism of the Andes. En Galaty, J. G. y Johnson, D. L. (Eds.). The World of Pastoralism: Herding Systems in Comparative Perspective (pp. 323-52). Nueva York: Guilford Press.

Buitrago, L. G. (1999). El clima de la provincia de Jujuy. San Salvador de Jujuy, Argentina: Facultad de Ciencias Agrarias de la Universidad Nacional de Jujuy, Argentina.

Carreras, J. (2015). Fogones, hornos, cocinas y fuegueros de Cusi-Cusi (Puna de Jujuy). Análisis etnoarqueológico de las prácticas domésticas pastoriles vinculadas a las estructuras de combustión (Tesis de Licenciatura). Facultad de Filosofía y Letras, Universidad de Buenos Aires, Argentina.

Castro, V., Varela, V., Aldunate, C. y Araneda, E. (2004). Principios orientadores y metodología para el estudio del Qhapaqñan en Atacama: desde El Portezuelo del Inka hasta Río Grande. Chungara Revista de Antropología Chilena, 36(2), 463-481.

Chang, C. y Koster, H. A. (1986). Beyond Bones: Toward an Archaeology of Pastoralism. Advances in Archaeological Method and Theory, 9, 97-148. 
Cribb, R. (1991). Nomads in Archaeology. New Studies in Archaeology. Cambridge: Cambridge University Press.

Debedenetti, S. (1930). Chulpas en las cavernas del río San Juan Mayo. Buenos Aires: Imprenta de la Universidad de Buenos Aires.

De Feo, C., Fernández, A. M. y Raviña, G. (2004). Pajchela y Guayatayoc: dos sitios incaicos en la puna Noroccidental Jujeña. En Libro de resúmenes del XV Congreso Nacional de Arqueología Argentina (p. 104). Río Cuarto: Universidad Nacional de Río Cuarto.

Denevan, W. (1980). Tipología de configuraciones agrícolas prehispánicas. América Indígena, 1(4), 619-651.

Díaz, A. (2013). Aguas ausentes e historias hendidas. Tecnología de riego y organización social del trabajo agrícola en el primer milenio a.D. (Laguna Blanca-CatamarcaArgentina). En Gordillo, I. y Vaquer, J. M. La espacialidad en arqueología. Enfoques, métodos y aplicación (pp. 101-150). Quito: Abya-Yala.

Dollfus, O. (1991). Territorios andinos: reto y memoria. Lima: Instituto Francés de Estudios Andinos - Instituto de Estudios Peruanos.

Donkin, R. A. (1979). Agricultural Terracing in the Aboriginal New World. Tucson, AZ: University of Arizona Press.

Enríquez Salas, P. (2000). El diálogo con las señas en la agricultura andina. En Van Kessel, J. y Larraín Barros, H. (Eds.). Manos sabias para criar la vida. Tecnología Andina (pp. 248-272). Quito: Abya-Yala.

Erickson, C. L. (2006). Intensification, political economy, and the farming community. Defense of a bottomup perspective of the past. En Marcus, J. y Stanish, C. (Eds.). Agricultural Strategies (pp. 233-265). Los Angeles, CA: Cotsen Institute.

Flores Ochoa, J. A. (1968). Los Pastores de Paratía. Una introducción a su estudio. México, DF: Instituto Indigenista Interamericano.

García, S., Rolandi, D., López, M. y Valeri, P. (2002). Alfa', vega y hortaliza. Riego y siembra en Antofagasta de la Sierra, Puna catamarqueńa. Relaciones de la Sociedad Argentina de Antropología, XXVII, 79-100.
García, S., Rolandi, D., Valeri, P. y López, M. (2004). La costumbre y la Ley en un pequeño sistema de riego: Antofagasta de la Sierra, altiplano andino argentino. Boletín Archivo Histórico del Agua, 24, 23-35.

Göbel, B. (2002). La arquitectura del pastoreo: Uso del espacio y sistema de asentamientos en la Puna de Atacama (Susques). Estudios Atacameños, 23, 53-76.

Gonnet, J. M., López, C., Aranibar, D., y Lictevout, E. (2016). Manual introductorio al manejo de vegas y bofedales mediante prácticas tradicionales de culturas andinas en el norte de Chile. Arica, Chile: Corporación Norte Grande.

Gose, P. (2004). Aguas mortiferas y cerros hambrientos: rito agrario y formación de clases en un pueblo andino. Quito: Abya-Yala.

Guagliardo, J. (2011). Paisajes agrarios, ancestralidad y conflicto durante el periodo de Desarrollos Regionales Tardio (ca. 1200 -1450 DC) en el altiplano de Lipez (Potosí, Bolivia): coyunturas, escalas y cambio social (Tesis doctoral). Facultad de Filosofía y Letras, Universidad de Buenos Aires, Argentina.

Guber, R. (2001). La etnografía, método, campo y reflexividad. Bogotá: Grupo Editorial Norma.

Haber, A. (1991). La estructuración del recurso forrajero y el pastoreo de camélidos. Actas del XI Congreso Nacional de Arqueología Chilena, tomo II (pp. 139-150). Santiago de Chile.

Haber, A. (1992). Pastores y pasturas. Recursos forrajeros en Antofagasta de la Sierra (Catamarca), en relación a la ocupación formativa. Shincal, 2, 15-23.

Haber, A. (2006). Una arqueología de los oasis puneños. Domesticidad, interacción identidad en Antofalla. Primer y segundo milenios d.C. Córdoba: Universidad del Cauca y Jorge Sarmiento Editor Universitaslibros.

Ingold, T. (1993). The Temporality of the Landscape. World Archaeology, 25(2), 152-174.

Ingold, T. (2000). The Perception of the Environment. Essays on livelihood, dwelling and skill. London/New York: Routledge. 
Khazanov, A. (1994). Nomads and the Outside World. Cambridge: Cambridge University Press.

Lane, K. (2006a). Engineering the Puna: the hydraulics of agro-pastoral communities in a north-central Peruvian valley (Tesis doctoral). University of Cambridge, Cambridge, Inglaterra.

Lane, K. (2006b). Mirando a través del espejo: re-evaluando el rol del agropastoralismo en la Sierra Norcentral Andina. En Herrera, A., Orsini, C. y Lane, K. (Eds.). La Complejidad Social en la Sierra de Ancash: ensayos sobre paisaje, economía y continuidades culturales (pp. 19-34). Milano, Italia/Lima, Perú: Civiche Raccolte d'Arte Applicata del Castello Sforzesco- Raccolte Extraeuropee - PUNKU Centro de Investigación Andina, Lima.

Lane, K. (2010). ¿Hacia dónde se dirigen los pastores? Un análisis del papel del agropastoralismo en la difusión de las lenguas en los Andes. Boletín de Arqueología PUCP, 14, 181-198.

Lema, V. (2014). Criar y ser criados por las plantas y sus espacios en los Andes Septentrionales de Argentina. En Benedetti, A. y Tomasi, J. (Comps.). Espacialidades altoandinas. Nuevos aportes desde la Argentina. Tomo I: Miradas hacia lo local, lo comunitario y lo doméstico (pp. 301-338). Buenos Aires: Editorial de la FFyL de la Universidad de Buenos Aires.

Maldonado Fonkén, M. S. (2014-15). An introduction to the bofedales of the Peruvian High Andes. Mires and Peat, 15, 1-13.

Mamaní, M. (1988). Agricultura a los 4000 metros. En Albó, X. (Comp.). Raíces de América: El Mundo Aymara (pp. 75-129). Madrid: Alianza Editorial.

Merlino, R. y Rabey, M. (1978). El ciclo agrario-ritual en la Puna Argentina. Relaciones de la Sociedad Argentina de Antropologia, XII, 47-70.

Nielsen, A. E. (2000). Andean Caravans: An ethnoarchaeo$\log y$ (Tesis doctoral). Universidad de Arizona, Arizona, EUA.

Nielsen, A. E. (2003). Ocupaciones prehispánicas de la etapa agropastoril en la Laguna de Vilama (Jujuy, Argentina). Cuadernos, 20, 81-108.
Nielsen, A. E. (2018). Chullpas y sociedad en la historia prehispánica tardía del Altiplano Sur. En Muñoz Collazos, M. A. (Ed.). Interpretando Huellas: Arqueología, Etnohistoria y Etnografía de los Andes y sus Tierras Bajas (pp. 569-588). Cochabamba: Grupo Editorial Kipus.

Olivera, D. (2001). Sociedades agropastoriles tempranas: el Formativo Inferior del Noroeste Argentino. En Berberián, E. y Nielsen, A. (Eds.). Historia Argentina Prehispánica (pp. 83-125). Córdoba, Argentina: Editorial Brujas.

Orlov, D. S., Karavanova, E. I. y Pankova, E. (1992). Effect of readily soluble salts on the spectral reflectivity of soils of the serosem zone. Eurasian Soil Science, 24(1), 104-118.

Oyarzabal, M., Clavijo, J., Oakley, L., Biganzoli, F., Tognetti, P., Barberis, I., Maturo, H. M., Aragón, R., Campanello, P. I., Prado, D., Oesterheld, M. y León, R. (2018). Unidades de vegetación de la Argentina. Ecología Austral, 28, 40-63.

Palacios Ríos, F. (1977). Pastizales de regadío para alpacas. En Flores Ochoa, J. (Ed.). Pastores de puna. Uywamichiq punarunakuna (pp. 155-170). Lima: Instituto de Estudios Peruanos.

Palacios Ríos, F. (1988). Pastores de Llamas y Alpacas. En Albó, X. (Ed.). Raíces de América. El Mundo Aymara (pp. 133-151). Madrid: Alianza América/Unesco.

Pey, L. (2016). Donde convergen los rios: Una interpretación del paisaje agricola de Casas Quemadas (Quebrada de Pajchela, Puna de Jujuy) durante el Periodo Tardio/Inka (ca. 1450-1536 años d.C.) (Tesis de licenciatura). FFyL, Universidad de Buenos Aires, Argentina.

Pey, L. (2017a). Diseño metodológico para un modelo funcional productivo del entorno de un sitio agrícola andino. La Zaranda de Ideas. Revista de Jóvenes Investigadores en Arqueología, 15(2), 113-133.

Pey, L. (2017b). Nuevas formas, ¿viejos saberes? El caso de la Cooperativa Agrícola de Comunidades Altoandinas Limitada (CADECAL) (Puna de Jujuy, Argentina). En MINAGRI, FAO, UNALM (Presidencia). Simposio Aspectos socioculturales y arqueológicos. Resúmenes de exposiciones del VI Congreso Mundial de la Quinua y III Simposio Internacional de Granos Andinos, Perú, 2017. Puno, Perú, p. 9. 
Pey, L. y Bonelli, J. (2016). Cultivar en Casas Quemadas: Lógica Espacial y Prácticas agrícolas en un sitio de la quebrada de Pajchela (Puna de Jujuy) durante el Período Tardío/Inka (1450-1536 años d.C.). En Quesada, M. y Troncoso, A. Historias de paisajes agrarios. Simposio llevado a cabo en el XIX Congreso Nacional de Arqueología Argentina, San Miguel de Tucumán, Argentina.

Pey, L. y Carboni, B. (2018). Entre el campo y la academia. Otros caminos para la interpretación de los paisajes agrícolas de la Puna jujeña. En Eguía, L., Lane, K., Pey, L. y Orsi, J. P. IV Jornadas de Actualización del Instituto de Arqueología llevadas a cabo en el Instituto de Arqueología, FFyL, Universidad de Buenos Aires, Buenos Aires, Argentina.

Pey, L., Zuccarelli, V. y Carreras, J. (2015). Caracterización y análisis espacial del sitio agrícola Casas Quemadas (Rinconada, Jujuy) durante el Período Tardío/Inka (1450-1536 años d.C.). En Mercolli, P. y Vaquer, J. M. (Eds.). Libro de resúmenes de las Primeras Jornadas sobre el Altiplano Sur. Miradas Disciplinares (pp. 78). Tilcara, Argentina: FFyL, Universidad de Buenos Aires.

Quesada, M. (2001). Tecnología agricola y producción campesina en la Puna de Atacama (Tesis de licenciatura). Escuela de Arqueología, Universidad Nacional de Catamarca, San Fernando del Valle de Catamarca, Argentina.

Quesada, M. (2007). Paisajes agrarios en el área de Antofalla. Procesos de trabajo y escalas sociales de la producción agricola. (Primer y segundo milenios d.C.) (Tesis doctoral). Facultad de Ciencias Naturales y Museo, Universidad Nacional de La Plata, La Plata, Argentina.

Quesada, M. N. y Lema, C. (2007). ¿¿De quién son los potreros? Antagonismos en la interpretación de la lógica productiva campesina y de hacienda en la Puna de Atacama. Finales del XVIII y comienzos del XIX. En Presta, A. M. y Palomeque, S. (Presidencia), Sociedades indigenas y sistemas de dominación desde una perspectiva etnohistórica. Desde el Tawantinsuyu hasta la crisis del sistema colonial español. Simposio llevado a cabo en las XI Jornadas Interescuelas/Departamentos de Historia, San Miguel de Tucumán, Argentina.

Quesada, M. N. y Lema, C. (2011). Los potreros de Antofagasta: Trabajo indígena y propiedad (finales del siglo XVIII y comienzos del XIX). Andes. Antropología e Historia, 22(2), 247-273.
Rist, S. y San Martin, J. (1993). Agroecología y saber campesino en la conservación de suelos. Cochabamba, Bolivia: Agruco.

Saravia, T. S. (1960). Geografía de la Provincia de Jujuy. Buenos Aires: Instituto Geográfico Militar.

Squeo, F. A., Veit, H., Arancio, G., Gutiérrez, J. R., Arroyo, M. T. y Olivares, N. (1993). Spatial heterogeneity of high mountain vegetation in the Andean desert zone of Chile. Mountain Research and Development, 13(2), 203-209.

Squeo, F. A., Warner, B. G., Aravena, R. y Espinosa, D. (2006). Bofedales: high altitude peatlands of the central Andes. Revista Chilena de Historia Natural, 79, 245-255.

Suetta, J. M. (1967). Construcciones agrícolas prehispánicas en Coctaca (Prov. de Jujuy). Antiquitas, 4,1-9.

Tello, E. (1999). La formación histórica de los paisajes agrarios mediterráneos: una aproximación coevolutiva. Historia Agraria, 19, 195-212.

Tilley, C. (1994). A Phenomenology of Landscape. Places, Paths and Monuments. Oxford: Berg.

Tomasi, J. (2011). Geografías del pastoreo. Territorios, movilidades y espacio doméstico en Susques (Provincia de Jujuy) (Tesis doctoral inédita). Universidad de Buenos, Buenos Aires, Argentina.

Torres, G., Lupo, L., Sánchez, A. y Schittek, K. (2012). Aportes a la flora polínica de turberas altoandinas, Provincia de Jujuy, noroeste argentino. Gayana Bot., 69(1), 30-36.

Treacy, J. M. (1994). Las chacras de Coporaque. Andenería y riego en el Valle del Colca. Lima, Perú: Instituto de Estudios Peruanos.

Van Kessel, J. y Enríquez Salas, P. (2002). Señas y señaleros de la santa tierra. Agronomia Andina. Quito, Ecuador/ Iquique, Chile: Abya-Yala - IECTA.

Vaquer, J. M. (2011). Paisaje, Materialidad y Prácticas Sociales en Cruz Vinto. Una interpretación desde los espacios domésticos externos. Saarbrücken, Alemania: Editorial Académica Española.

Vaquer, J. M. (2013) La tradición como límite de la interpretación. Un ejemplo desde Cruz Vinto (Norte de Lípez, Bolivia). Relaciones de la Sociedad Argentina de Antropología, 38(2), 269-291. 
Vaquer, J. M. (2016). La ocupación colonial temprana (S. XVI y XVII) en Casas Quemadas (Cusi Cusi, Rinconada, Jujuy): primeras aproximaciones a las relaciones entre lo global y lo local. Revista de Arqueología Histórica Argentina y Latinoamericana, 10(2), 1-26.

Vaquer, J. M. y Cámera, Y. (2018). Las relaciones entre el paisaje, las narrativas y la praxis arqueológica en Cusi Cusi (Rinconada, Jujuy): una mirada hermenéutica. Revista del Museo de La Plata, 3(1), 38-56.

Vaquer, J. M., Gerola, I., Carboni, B. y Bonelli, J. (2014). Cazadores, pastores y agricultores. Lógicas del paisaje en Cusi-Cusi, cuenca superior del Río San Juan Mayo (Jujuy, Argentina). En Beierlein de Gutiérrez, M. y Gutierrez, D. (Eds.). Desarrollos Regionales (1000-1500 DC) en el Sur de Bolivia y el Noroeste Argentino (pp. 30-46). Tarija, Bolivia: La pluma del escribano.

Vaquer, J. M., Zuccarelli, V., Pey, M. L. y Cámera, Y. (2014). Paisajes agrícolas de la dominación y sus relaciones interregionales: el caso de Casas Quemadas (Cuenca
Superior del Río San Juan Mayo, Jujuy, Argentina). En Beierlein de Gutiérrez, M. y Gutiérrez, D. (Eds.). Desarrollos Regionales (1000-1500 DC) en el Sur de Bolivia y el Noroeste Argentino (pp. 47-63). Tarija, Bolivia: La pluma del escribano.

Villagrán, C. y Castro, V. (1997). Etnobotánica y manejo ganadero de las vegas, bofedales y quebradas en el Loa Superior, Andes de Antofagasta, Segunda Región, Chile. Chungara, 29(2), 275-304.

Yacobaccio, H. D. (2013). Towards a Human Ecology for the Middle Holocene in the Southern Puna. Quaternary International, 307, 24-30.

Yacobaccio, H., C. Madero, C., y Malmierca, M. (1998). Etnoarqueología de pastores surandinos. Buenos Aires: GZC. 